

\section{Sumário}

I. CRônicas

A Favor de uma Corte Latino-Americana de Justiça ..................................................... 3 Nitish Monebhurrun

Sobre A SOluÇão JUdicial de CONTROvérsias Na AMÉRICA LATINA 7 Lucas Carlos Lima

A Favor de uma Corte Latino-Americana de Justiça - Uma Reação sobre a Legalidade e A Legitimidade De Seu Desenho Institucional............................................................15

Arthur Roberto Capella Giannattasio

O Estudo do Direito Internacional sob uma Nova Perspectiva: Nossa Experiência na Philip C. Jessup International Moot Court Competition............................................20 Ana Vitória Muniz Bokos, Igor Medeiros Maia, Jefferson Seidy Sonobe Hable, Gabriel de Oliveira Borba, Gilda Nogueira Paes Cambraia e Nayara Lima Rocha Da Cruz

Revisión de laudos de arbitrajes de inversión 2019: I Encuentro Anual (Santiago de

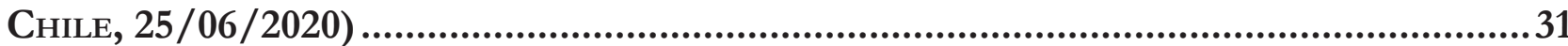
Andrés Delgado Casteleiro e Ivette Esis

II. Dossiê: Populismo e Direito Internacional / Populism and Internatio-

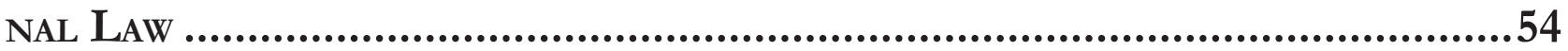

Editorial: Populism and International Law: Global South Perspectives .56 Lucas Lixinski e Fabio Morosini

Editorial: Populismo e Direito Internacional: Perspectivas do Sul Global .61 Lucas Lixinski e Fabio Morosini 
Between Science and populism: the Brazilian Response to COVID-19 from the Perspective of the legal determinants of Global Health

Deisy de Freitas Lima Ventura e Jameson Martins

Populism, ENVIronmental LAW, AND THE POST-PANDEMiC ORDER Alessandra Lehmen

Populism and the Evangelical church in Latin America: how anti-LGBTI forces TRIED TO STOP THE COLOMBIAN PEACE AGREEMENT Julia Assmann de Freitas Macedo e Fabrízio Conte Jacobucci

“Deus EM Davos": o Direito INTERnACIONAL ENTRE REACIONÁRIOS E NEOLIBERAIS NO GOVERNO BOLSONARO 121

Lucas Tasquetto e João Roriz

CHINESE POPULISM IN THE 1920s, EXTRATERRITORIALITY AND INTERNATIONAL LAW 139 Wanshu Cong

CONCEPTUALIZING UNILATERALISM, FRAGMENTATIONISM AND STATISM IN A POPULISM CONTEXT: A RISE OF POPULIST INTERNATIONAL LAW? 162 Wei Shen e Carrie Shu Shang

AUTONOMÍA ADMINISTRATIVA SIN AUTONOMÍA POLÍTICA: LA APLICACIÓN DEL MODELO "UN PAÍS dos SISTEMAs" eN HoNg Kong 186 Juan Enrique Serrano Moreno

III. Artigos sobre outros temas...................................................... 197

Um TWAiler entre nós? As contribuições de Celso Duvivier de Albuquerque Mello PARA O DIREITO INTERNACIONAL (CRÍTICO) NO BRASIL .................................................... 199

Fabio Morosini e Matheus Leichtweis

DEMOCRACIES IN DANGER: ARE JUDICIAL DIALOGUES MEANS TO REFRAIN SETBACKS IN LATIN America?.

Melina Girardi Fachin e Bruna Nowak 


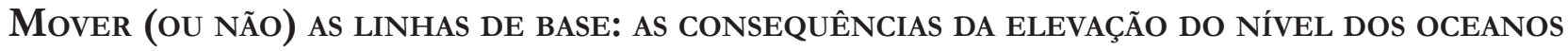
SOBRE AS ZONAS MARÍTIMAS DOS PEQUENOS ESTADOS INSULARES EM DESENVOLVIMENTO E AS ALTERNATIVAS JURÍDICAS PARA REDUZIR SEUS IMPACTOS

Alexandre Pereira da Silva

A mineração em águas profundas no Pacífico 263 Pierre-Jean Bordahandy

Dual Nationality and International Law in times of Globalization. Challenges and Opportunities for Consular Assistance and Diplomatic Protection in RECENT CASES. 288

Walter Arevalo-Ramirez e Robert Joseph Blaise Maclean

Expulsion of aliens: the application of International Law by Chilean Superior Courts 309

Regina Ingrid Díaz Tolosa

O TIPO PENAL BRASILEIRO DE PROMOÇÃo DE MIGRAÇÃO ILEGAL E O PRINCÍPIO DA NÃO CRIMINALIZAÇÃo DA MOBILIDADE HUMANA

Regina Cândido Lima e Silva Santos e Deilton Ribeiro Brasil

INDICADORES TRANSNACIONAIS DE CORRUPÇÃO AMBIENTAL: A OPACIDADE NA TRANSPARÊNCIA INTERNACIONAL

Márcio Ricardo Staffen

SubTRAÇÃo INTERNACIONAL DE CRIANÇAS: ANÁLISE DAS EXCEÇÕES AO RETORNO IMEDIATO DO MENOR À RESIDÊNCIA HABITUAL E CRÍTICA AO ENQUADRAMENTO DA VIOLÊNCIA DOMÉSTICA COMO FLEXIBILIDADE PERMISSIVA

Vivian Daniele Rocha Gabriel

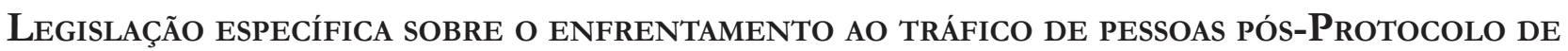
Palermo (2000): análise do Estado de Moçambique 383

Mercia Cardoso de Souza, Guirino Dinis José Nhatave e Francisco Horácio da Silva Frota 
IV. Artigos traduzidos

DIREITO INTERNACIONAL DO RECONHECIMENTO

Emmanuelle Tourme-Jouannet e Tradutor: Ademar Pozzatti Junior

V. RESENHAS

Fabio Costa Morosini, Gabriel Lee Mac Fadden Santos, Valentina Fonseca da Luz e Vinicius Tejadas Maia 


\title{
Legislação específica sobre o enfrentamento ao tráfico de pessoas pós-Protocolo de Palermo (2000): análise do Estado de Moçambique*
}

\author{
Specific legislation targeting human \\ trafficking after the approval of Palermo \\ Protocol 2000: Mozambique State case
}

* Recebido em 22/08/2020

Aprovado em 12/10/2020

** Doutora em Direito Constitucional pela Universidade de Fortaleza (UNIFOR/CE), com estágio pré-doutoral no Departamento de Estudios Internacionales de Universidad Loyola Andalucía (LOYOLA, Sevilha, Espanha). Mestra em Direito Público pela Pontifícia Universidade Católica de Minas Gerais (Bolsa - CAPES). Graduada em Serviço Social pela Universidade Estadual do Ceará e em Direito pela UNIFOR/ CE. Coordenadora da linha de pesquisa Direitos Humanos, inserida no grupo de pesquisa Dimensões de Conhecimento do Poder Judiciário, da Escola Superior da Magistratura do Estado de Ceará (ESMEC). Professora da Faculdade Luciano Feijão

E-mail: merciacardosodesouza@gmail.com

*** Doutorando em Políticas Públicas pelo Programa de Pós-Graduação em Políticas Públicas da Universidade Estadual do Ceará (UECE). Mestre em Relações Internacionais e Diplomacia, com especialidade em Política Externa, pelo Instituto Superior de Relações Internacionais (ISRI). Pesquisador da linha de pesquisa Direitos Humanos, inserida no grupo de pesquisa Dimensões de Conhecimento do Poder Judiciário, da Escola Superior da Magistratura do Estado de Ceará (ESMEC) e do grupo de pesquisa Núcleo de Autos Estudos em Políticas de Segurança e Cidadania (NAEPS), da UECE. Bolsista do Programa de Estudantes-Convênio de Pós-Graduação, da CAPES-Brasil. E-mail: desgui69@gmail.com.

Doutor em Sociologia Política pela Universidad de Salamanca (Espanha). Mestre em Educação pela Universidade Estadual do Ceará (UFC/CE). Graduado em Ciências Sociais pela Universidade de Fortaleza (UNIFOR/CE). Professor Associado da Universidade Estadual do Ceará (UECE). Coordenador do Programa de Pós-Graduação em Políticas Públicas da UECE. Email: fhsfgm@gmail.com

\author{
Mercia Cardoso de Souza** \\ Guirino Dinis José Nhatave*** \\ Francisco Horácio da Silva Frota****
}

\section{Resumo}

O Protocolo de Palermo (2000) informa que uma ação eficaz para prevenir e combater o tráfico de pessoas exige, por parte dos países de origem, trânsito e destino, uma abordagem global e internacional. Destarte, o Protocolo prevê, no artigo $9^{\circ}$, que os Estados-Membros deverão estabelecer políticas, programas e outras medidas abrangentes para prevenir e combater o tráfico de pessoas e proteger as vítimas desse grave ilícito. Em virtude dessa recomendação, o instrumento avançou no enfrentamento ao crime, uma vez que inspira e articula ações dos Estados e outros atores no enfrentamento a essa prática que viola a dignidade da pessoa. Mediante o recurso da pesquisa bibliográfica e documental, o artigo analisa a legislação moçambicana sobre a prevenção e combate ao tráfico de pessoas. Com efeito, recorreu-se ao levantamento de documentos sobre a temática [tratados internacionais, regionais e legislação penal nacional [Lei n. 6/2008 e Lei n. 35/2014, Lei específica sobre tráfico de pessoas e Código penal, respectivamente)], assim como informações que constam da base de dados do Escritório das Nações Unidas contra Drogas e Crime (UNODC), seus respectivos relatórios globais e publicações oficiais que enfocam os direitos humanos. A pesquisa concluiu que o Protocolo de Palermo (2000) influenciou Moçambique na formulação de políticas públicas, apesar de existirem lacunas decorrentes da falta de regulamentação da Lei específica, e do fato de não haver um plano de ação nacional. Denota-se, igualmente, o não envio de informações sobre casos julgados para a base de dados do UNODC, o que minimiza os esforços de Moçambique.

Palavras-chave: Protocolo de Palermo. Lei n. 6/2008. Tráfico de Pessoas. Moçambique. 


\section{Abstract}

The Palermo Protocol (2000) informs that effective action to prevent and combat trafficking in persons requires, on the part of countries of origin, transit and destination, a global and international approach. Thus, the Protocol provides, in Article 9, that Member States should establish policies, programs and other comprehensive measures to prevent and combat trafficking in persons and protect victims of this serious crime. As a result of this recommendation, the instrument has advanced in tackling crime, as it inspires and articulates actions by States and other agents in tackling this practice that violates the dignity of the person. Using bibliographic and documentary research, the article analyzes Mozambican legislation on preventing and combating human trafficking. In fact, documents were collected on the subject [international, regional treaties and national criminal legislation [Law no. 6/2008 and Law no. 35/2014, Specific Trafficking in Persons Act and Penal Code, respectively)], as well as information contained in the United Nations Office on Drugs and Crime (UNODC) database, its respective global reports and official publications focusing on human rights. The research concluded that the Palermo Protocol (2000) influenced Mozambique in the formulation of public policies, despite the existence of gaps resulting from the lack of regulation of the specific Law, as well as the fact that there is no national action plan. It also denotes the failure to send information on judged cases to the UNODC database, which minimizes the Mozambique's efforts.

Keywords: Palermo Protocol. Law no. 6/2008. Trafficking in persons. Mozambique.

\section{Introdução}

O tráfico de pessoas preocupa todo o mundo, conforme divulgado nos diversos relatórios elaborados pelo Escritório sobre Drogas e Crime da Organização das Nações Unidas (UNODC) ${ }^{1}$. O recente Relatório Global

O Escritório das Nações Unidas contra Drogas e Crime (UNODC) baseia seu trabalho nas três convenções internacionais de controle de drogas, nas convenções contra o crime organizado transnacional e contra a corrupção e nos instrumentos internacionais contra o terrorismo. Nesse âmbito, o escritório publicou, desde 2009, cinco relatórios globais (Relatório Global sobre Tráfico de sobre Tráfico de Pessoas de 2018 aponta que mais de 70\% das pessoas afetadas pelo tráfico na contextura global são do sexo feminino. Os dados evidenciam que o tráfico de pessoas afeta mais seres humanos a cada ano, possuindo o recorte de gênero, porquanto a maior parte das vítimas é composta por mulheres adultas (49\%) e adolescentes (meninas) (23\%). Os homens constituem $21 \%$ das vítimas e os meninos $7 \%{ }^{2}$.

Enquanto a maioria das vítimas de exploração sexual é do sexo feminino, os homens formam o maior grupo nos casos de trabalho forçado. Embora a finalidade mais divulgada seja o tráfico de pessoas para exploração sexual, milhares de vítimas também trabalham em condições, análogas à escravidão, em serviços domésticos e em setores como mineração, pesca e, às vezes, são utilizadas para a mendicância infantil e o tráfico para remoção de órgãos humanos. ${ }^{3}$ As mesmas finalidades são relatadas pelos Relatórios sobre Tráfico de Pessoas de $2016^{4}, 2014^{5}$ e $2012^{6}$. Os citados documentos constatam o aumento de casos de trabalho forçado e da exploração sexual. A par disso, esforços estão sendo desenvolvidos pelos países com vistas a adotarem, aprovarem e ratificarem instrumentos normativos internacionais $\mathrm{e}$ de regiões, assim como de aprovarem legislações domésticas para o enfrentamento ao tráfico de pessoas, aí se destacando, por exemplo, no plano internacional, um

Pessoas de 2009, 2012, 2014, 2016 e 2018). Paralelamente a estes, há outras publicações, que abordam sobre temáticas específicas relacionadas ao tráfico de pessoas, nomeadamente: planos, manuais entre outras (UNODC. Publicações UNODC. 2020. Disponível em: $<$ https://www.unodc.org/lpo-brazil/pt/trafico-de-pessoas/publicacoes.html>. Acesso em: 22 jun. 2020.

2 UNODC. Relatório Global sobre o Tráfico de Pessoas 2018. Nova York: Publicação das Nações Unidas. 2018. Disponível em: https://www.unodc.org/documents/lpo-brazil//Topics_TIP/Publicacoes/TiP_PT.pdf. Acesso em: 22 maio 2020.

3 UNODC. Relatório Global sobre o Tráfico de Pessoas 2018. Nova York: Publicação das Nações Unidas. 2018. Disponível em: https://www.unodc.org/documents/lpo-brazil//Topics_TIP/Publicacoes/TiP_PT.pdf. Acesso em: 22 maio 2020.

4 UNODC. Global Report on Trafficking in Persons in 2016. Nova York: Publicação das Nações Unidas. 2016. p. 19. Disponível em: https:// www.unodc.org/documents/data-and-analysis/glotip/2016_Global_Report_on_Trafficking_in_Persons.pdf. Acesso em: 18 maio 2020.

5 UNODC. Global Report on Trafficking in Persons in 2014. Nova York: Publicação das Nações Unidas. 2014. Disponível em: https://www.unodc.org/documents/lpo-brazil//Topics_TIP/Publicacoes/GLOTIP_2014_full_report.pdf. Acesso em: 10 maio 2020.

6 UNODC. Global Report on Trafficking in Persons in 2012. Nova York: Publicação das Nações Unidas. 2012. Disponível em: https:// www.unodc.org/documents/data-and-analysis/glotip/Trafficking_ in_Persons_2012_web.pdf. Acesso em: 9 maio 2020 
aumento significativo na aprovação de legislação sobre tráfico de pessoas nos últimos dez anos ${ }^{7}$.

O tráfico de pessoas é um crime de natureza internacional e doméstica. Em virtude disso, a Organização das Nações Unidas aprovou, no ano de 2000, o Protocolo Adicional à Convenção das Nações Unidas contra o Crime Organizado Transnacional Relativo à Prevenção, Repressão e Punição do Tráfico de Pessoas, em Especial Mulheres e Crianças, conhecido como Protocolo de Palermo (2000), instrumento que provê uma definição de tráfico de pessoas acordada internacionalmente e deixou recomendações a serem seguidas pelos atores de modo a desenvolverem ações eficazes no seu enfrentamento. Em Moçambique, como resultado da revogação o art. 10 da Lei n. 6/2008, de 09 de julho — sobre a Prevenção e Combate ao Tráfico de Pessoas, especialmente Mulheres e Crianças, que definia o tráfico de pessoas atualmente, o referido ilícito penal é previsto e punido pelo Código Penal, aprovado pela Lei n. 35/2014, de 31 de dezembro.

Ressalte-se o fato de que um dos continentes onde há escassez de dados sobre o tráfico de pessoas e, consequentemente, lacunas significativas de conhecimento relacionadas ao panorama e fluxos de tráfico de pessoas, é o Africano, notadamente a África Subsaariana, além do Sul da Ásia e de algumas partes da Ásia Oriental. Em vista disso, o Relatório sobre Tráfico de Pessoas, de 2018, sugere como modo de minimizar esse problema, o desenvolvimento de pesquisas de campo e o reforço dos sistemas estatísticos nacionais sobre criminalidade e justiça penal ${ }^{8}$.

Em síntese, as modalidades predominantes de tráfico humano na África são: trabalho forçado em maior grau; exploração sexual; remoção de órgãos; e mendicância infantil ${ }^{9}$. Já, na África Austral, foram identificados casos de tráfico para rituais e práticas tradicionais ${ }^{10}$,

RABEN, Sarah Myers. The ISIS eradication of Christians and yazidis: human trafficking, denocide, and the missing international efforts to stop it. Revista de Direito Internacional, Brasília, v. 15, n. 1, p. 239-253, 2018.

8 UNODC. Relatório Global sobre o Tráfico de Pessoas 2018. Nova York: Publicação das Nações Unidas. 2018. Disponível em: https://www.unodc.org/documents/lpo-brazil//Topics_TIP/Publicacoes/TiP_PT.pdf. Acesso em: 22 maio 2020

9 UNODC. Relatório Global sobre o Tráfico de Pessoas 2018. Nova York: Publicação das Nações Unidas. 2018. Disponível em: https://www.unodc.org/documents/lpo-brazil//Topics_TIP/Publicacoes/TiP_PT.pdf. Acesso em: 22 maio 2020.

10 UNODC. Global Report on Trafficking in Persons in 2012. Nova York: Publicação das Nações Unidas. 2012. Disponível em: https:/ / mas também casos em que as vítimas são sujeitas à exploração sexual, à exploração laboral e ao trabalho forçado, ocorrendo de serem as vítimas do sexo feminino, especialmente adolescentes, as mais propensas à exploração sexual comercial e ao casamento, enquanto as vítimas do sexo masculino tendem ao trabalho forçado ${ }^{11}$.

O tráfico de pessoas na região da África Austral é condicionado por uma variedade de fatores. O Estudo elaborado pela Southern African Development Community ${ }^{12}$, em 2016, identificou, como fatores causais desse delito, pobreza, desemprego, calamidades naturais (inundações e secas), instabilidade política nos países de origem e falta de oportunidades de geração de rendimentos, associados a outros fatores de pressão - que incluem a epidemia de HIV/SIDA. De acordo, com a Organização das Nações Unidas para a Educação, a Ciência e Cultura (UNESCO),

[...] a recente história de conflito armado, situações extremas de deslocação e de perda, reconstrução, disrupção política e profundas marcas sociais, juntamente com a geografia específica do país e a pandemia da SIDA fazem com que Moçambique seja um alvo convidativo para o crime organizado. ${ }^{13}$

Em decorrência de tais circunstâncias, a mesma organização destaca o fato de que "Moçambique é um país de origem e de trânsito para actividades de tráfico de pessoas" 14 , posicionamento sustentado por Magode

www.unodc.org/documents/data-and-analysis/glotip/Trafficking_ in_Persons_2012_web.pdf. Acesso em: 9 maio 2020.

11 SADC. Tráfico de Pessoas na Região da SADC: Folheto Informativo sobre Políticas, p. 1-10, ago. 2016.

12 A SADC existe desde 1980, pois fundada no dia primeiro de abril deste ano, em Lusaka, Zâmbia. Desde essa data até 17 de agosto de 1992, quando transformada em SADC, foi conhecida por Conferência de Coordenação do Desenvolvimento da África Austral (SADCC). "A SADC foi criada ao abrigo do art. $2^{\circ}$ do Tratado da SADC por Estados-Membros representados pelos respectivos Chefes de Estado e de Governo ou seus representantes devidamente autorizados para liderarem o processo de integração económica da África Austral". (SADC. Manual Institucional de Identidade Institucional da SADC. Gaborone: Secretariado da SADC, 2017. p. 6), com objetivo de são alcançar, por via da integração regional, o desenvolvimento econômico, paz e segurança, aliviar a pobreza, melhorar o padrão e qualidade de vida dos povos da África Austral e apoiar os que são socialmente desfavorecidos. Tais objetivos, de acordo com o Tratado da SADC, devem ser alcançados por meio do aprofundamento da integração regional, baseado nos princípios democráticos e no desenvolvimento equitativo e sustentável.

13 UNESCO. Tráfico de Pessoas em Moçambique: Causas Principais e Recomendações. Police Paper, Paris, n. 14.1 (P), Série de relatórios sobre a pobreza, 2006.

14 UNESCO. Tráfico de Pessoas em Moçambique: Causas Principais e Recomendações. Police Paper, Paris, n. 14.1 (P), Série de relatórios sobre a pobreza, 2006. p. 10. 
et al., ao darem conta da noção de que, ao nível da região da África Austral, "Moçambique tem sido considerado o principal corredor do tráfico de pessoas, particularmente de mulheres e crianças" ${ }^{\prime 1}$.

Nesse marco, o presente trabalho, consoante expresso até aqui, tem por foco o tráfico de pessoas em Moçambique. Para a proposição deste trabalho, pois, além da introdução e das considerações finais, o artigo está dividido em três seções. $\mathrm{Na}$ introdução, traçou-se o panorama do tráfico de pessoas no Mundo, na África e em Moçambique. Na primeira seção, abordou-se o conceito de tráfico de pessoas adotado em Moçambique. No segundo segmento, discorreu-se sobre o contexto e gênese das políticas públicas formuladas pelo País para o enfrentamento da conjunção de problemas configurada no tráfico de pessoas, em resposta às recomendações do Protocolo de Palermo (2000). No módulo três, explanou-se a respeito dos desafios de coleta de dados de jurisprudência em Moçambique, assim como em relação às desvantagens que o País experiencia, por não proceder ao envio de tais indicadores para a base de dados da UNODC. Nas considerações finais, elaborou-se uma breve análise com suporte nos indicativos analisados no decorrer do escrito.

\section{Conceito de Tráfico de Pessoas em Moçambique}

Em Moçambique, há "evidência de tráfico de pessoas a nível interno" "16, uma situação que se verifica, "normalmente das zonas rurais para as zonas urbanas"17, onde o tráfico se traduz em fenômeno complexo, cuja origem se observa na sua interação com a pobreza, a migração de mão de obra, conflitos ou convulsões políticas que provocam deslocamentos populacionais ${ }^{18}$.

Mencionado crime, de acordo com o Fundo das Nações Unidas para a Infância (UNICEF), alberga um

\footnotetext{
15 MAGODE, Joaquim; JOSÉ, Patrício; CONGOLO, Frederico; CADEADO, Calton; PATRÍCIO, António; LINDY, Rafael. Tráfico de Pessoas em Moçambique, em particular de crianças. Moçambique: Procuradoria Geral da República, 2014. p. 2.

16 UNESCO. Tráfico de Pessoas em Moçambique: Causas Principais e Recomendações. Police Paper, Paris, n. 14.1 (P), Série de relatórios sobre a pobreza, 2006. p. 10.

17 FDC. Violência contra Menores em Moçambique: revisão da literatura. Maputo: KULA Estudos e Pesquisa Aplicada, 2008. p. 23.

18 FDC. Violência contra Menores em Moçambique: revisão da literatura. Maputo: KULA Estudos e Pesquisa Aplicada, 2008
}

aspecto característico, que pressupõe um movimento coercivo, ilícito e clandestino de pessoas, com o objetivo de submetê-las à exploração sexual ou econômica, mediante atividades, tais como trabalho doméstico, casamento falso, emprego clandestino, adoção dissimulada, entre outras anomalias, reunindo, na sua maioria, mulheres, crianças e adolescentes ${ }^{19}$.

Estudos realizados em Moçambique apontam, igualmente, para a ocorrência do tráfico de órgãos, partes, tecidos e fluidos do corpo humano. Foi publicado, por exemplo, o Estudo sobre tráfico de órgãos e partes do corpo bumano na Região Sul de Moçambique, editado em 2016, elaborado por Esmeralda Mariano, Carla Braga e Andreia Moreira. Tem curso, ainda, o Estudo sobre tráfico de pessoas, órgãos e partes do corpo bumano no norte de Moçambique, publicado em 2018, por Andreia Moreira e Esmeralda Mariano. O primeiro, direcionado às Províncias de Maputo (Cidade e Província), Gaza e Inhambane, concluiu que o "[...] fenómeno de tráfico de órgãos humanos começa a ser objecto de atenção a partir de 2003"20, envolvendo uma rede complexa de intervenientes (traficantes, intermediários, os que extraem os órgãos, médicos tradicionais), com a finalidade de utilização desses órgãos na Medicina tradicional e moderna.

Já o ensaio realizado na Região Norte (Niassa, Cabo Delgado e Nampula) constatou que o tráfico de órgãos e partes do corpo humano tem como finalidade "alimentar" a Medicina tradicional, em “[...] rituais, para fabricar drogas ou remédios, [...] para fortificar, para a pessoa ter mais poder" ${ }^{21}$. O mesmo estudo identificou a situação do tráfico de pessoas com albinismo ${ }^{22}$, cuja ocorrência é justificada em crenças de feitiçaria, e o tráfico de pessoas, particularmente de mulheres, conduzidas para a exploração sexual. Essa constatação é, igualmente,

\footnotetext{
19 UNICEF. Proteção da criança: Manual para Parlamentares n. 7. Suíça: União Inter parlamentar, 2004.

20 MARIANO, Esmeralda; BRAGA, Carla; MOREIRA, Andrea. Estudo sobre o Tráfico de órgãos e partes de corpo bumano na Região Sul de Moçambique. Maputo: CEMIRDE, 2016.

21 MOREIRA, Andrea; MARIANO, Esmeralda. Estudo sobre o Tráfico de Pessoas, órgãos e artes de corpo bumano no Norte de Moçambique. Maputo: CEMIRDE, 2018. p. 68.

22 De acordo com uma publicação da organização não governamental KANIMAMBO, que aborda sobre o enquadramento da situação do albinismo em Moçambique, o albinismo é uma anomalia genética caracterizada por insuficiência de melanina, substância responsável pela coloração da pele, cabelos e olhos. (KANIMAMBO. Breve enquadramento da situação actual em Moçambique. 2020. Disponível em: https://www.uccla.pt/sites/default/files/mk_doc_ enquadramento_18set_2.pdf. Acesso em: 25 jun. 2020).
} 
aferida pelo Informe da Anistia Internacional 2017/2018, que relata sobre os ataques sofridos por pessoas com albinismo em Malawi e Moçambique, onde elas são sequestradas e mortas com vistas ao uso de partes de seu corpo para superstição ${ }^{23}$. Acerca de semelhante aspecto, importa, ainda, referir o fato de que a África Austral foi identificada pelo Relatório sobre Tráfico de Pessoas, de 2012, como região com ocorrência de casos de tráfico para rituais e práticas tradicionais ${ }^{24}$.

A exploração das vítimas, nas modalidades especificadas anteriormente, constitui "uma ameaça à segurança e à dignidade humana" ${ }^{\prime 25}$, por intermédio da violação dos seus direitos humanos ${ }^{26}$, uma vez que atenta contra a vida e a integridade física, psíquica e moral dos cidadãos. Impende recordar-se de que a segurança da pessoa contra quaisquer ameaças deve ser entendida como preocupação universal, visto que, nos termos do art. $3^{\circ}$ da Declaração Universal dos Direitos Humanos (DUDH $)^{27}$, "Todo ser humano tem direito à vida, à liberdade e à segurança pessoal", princípio reafirmado, no plano continental, pela Carta Africana dos Direitos Humanos e dos Povos, de $1979^{28}$, ao expressar, no ar-

23 ANISTIA INTERNACIONAL. Informe 2017/2018 sobre o Estado dos Direitos Humanos no Mundo. Reino Unido: Amnesty International, 2018.

24 UNODC. Global Report on Trafficking in Persons in 2012. Nova York: Publicação das Nações Unidas. 2012. Disponível em: https:/ / www.unodc.org/documents/data-and-analysis/glotip/Trafficking in_Persons_2012_web.pdf. Acesso em: 9 maio 2020.

25 MAGODE, Joaquim; JOSÉ, Patrício; CONGOLO, Frederico; CADEADO, Calton; PATRÍCIO, António; LINDY, Rafael. Tráfico de Pessoas em Moçambique, em particular de crianças. Moçambique: Procuradoria Geral da República, 2014. p. 14.

26 UNESCO. Tráfico de Pessoas em Moçambique: Causas Principais e Recomendações. Police Paper, Paris, n. 14.1 (P), Série de relatórios sobre a pobreza, 2006.

27 A Declaração Universal dos Direitos Humanos (DUDH) é um documento marco na história dos direitos humanos. A Declaração foi aprovada pela Assembleia Geral das Nações Unidas, em Paris, em 10 de dezembro de 1948, por meio da Resolução 217 A (III) da Assembleia Geral das Nações Unidas como uma norma comum a ser alcançada por todos os povos e nações. Ao todo, das 58 delegações que votaram, $\mathbf{4 8}$ votaram a favor e dez não votaram. [Tratase de um instrumento que estabelece, pela primeira vez, a proteção universal dos direitos humanos (NAÇÕES UNIDAS BRASIL. $A$ Declaração Universal dos Direitos Humanos de 1948. Disponível em: https://nacoesunidas.org/direitoshumanos/declaracao/>. Acesso em: 25 maio 2020)

28 A Carta Africana dos Direitos do Homem e dos Povos foi aprovada em Nairobi, Quénia, em julho de 1981, e ratificada por Moçambique por via da Resolução n. 9/88 de 25 de agosto de 1988 (OPHENTA. Carta Africana dos Direitos do Homem e dos Povos. Disponível em: https://www.ophenta.org.mz/wp-content/uploads/2017/03/Carta-Africana-Direitos-Humanos-1.pdf. Acesso em: 12 abr. 2020). tigo $6^{\circ}$, a ideia de que "todo indivíduo tem direito à liberdade e à segurança da sua pessoa" ${ }^{\prime 29}$.

De acordo com a UNESCO, esse fenômeno que, historicamente, se manifesta por intermédio de várias maneiras, se utiliza das vulnerabilidades da globalização, que propiciam a sua extensão à escala global, fato condicionante para que o crime adquira novas dimensões, que o traduzem num fenômeno complexo e multifacetado $^{30}$. Na mesma esfera, Arménio de Roda aponta a globalização como um fator conexo ao conceito da transnacionalidade. Seu posicionamento é justificado, por um lado, pela suscetibilidade da globalização, por se caracterizar pela abertura de múltiplos canais de comunicação entre os diversos pontos e, de outra parte, pela compreensão de que o tráfico de pessoas, além de possuir dimensões nacionais, também se exprime como um crime transfronteiriço e transnacional utilizando-se das vulnerabilidades e oportunidades por si oferecidas ${ }^{31}$.

Sob ponto de vista conceitual, Moçambique estabeleceu a definição de tráfico de pessoas, no âmbito jurídico, em 2008. Ela inspira-se no Protocolo de Palermo (2000), por ser um instrumento que prevê a primeira definição de tráfico de pessoas, acordada no patim internacional. Esse conceito, estabelecido pelo referido Protocolo, é utilizado, recorrentemente, por diversos autores, pesquisadores e em variados espaços onde se lida com matérias sobre o tráfico de pessoas. Essa predileção é notável em Moçambique, onde a $\mathrm{UNESCO}^{32}$, $\mathrm{FDC}^{33}$ e Magode $e^{2} a^{\beta 4}$, ao fazerem suas pesquisas acadêmico-profissionais, recorrem ao citado instrumento internacional para definir o tráfico de pessoas, como

[...] o recrutamento, o transporte, a transferência, o alojamento ou o acolhimento de pessoas, recorrendo

29 CARTA AFRICANA. Resolução n. 9/88, de 25 de agosto de 1981. Ratifica a Carta africana dos Direitos Humanos e dos Povos de 1979. Boletim da República: Conselho de Ministros. Maputo: Imprensa Nacional, 1981.

30 UNESCO. Tráfico de Pessoas em Moçambique: Causas Principais e Recomendações. Police Paper, Paris, n. 14.1 (P), Série de relatórios sobre a pobreza, 2006.

31 RODA, Arménio da. A dimensão global do tráfico bumano: o tráfico de pessoas aos olhos de Moçambique. São Paulo: Atarukas, 2019.

32 UNESCO. Tráfico de Pessoas em Moçambique: Causas Principais e Recomendações. Police Paper, Paris, n. 14.1 (P), Série de relatórios sobre a pobreza, 2006. p. 16.

33 FDC. Violência contra Menores em Moçambique: revisão da literatura. Maputo: KULA Estudos e Pesquisa Aplicada, 2008. p. 23.

34 MAGODE, Joaquim; JOSÉ, Patrício; CONGOLO, Frederico; CADEADO, Calton; PATRÍCIO, António; LINDY, Rafael. Tráfico de Pessoas em Moçambique, em particular de crianças. Moçambique: Procuradoria Geral da República, 2014. p. 26. 
à ameaça ou ao uso da força ou a outras formas de coação, ao rapto, à fraude, ao engano, ao abuso de autoridade ou de situação de vulnerabilidade ou à entrega ou aceitação de pagamentos ou benefícios para obter o consentimento de uma pessoa que tem autoridade sobre outra, para fins de exploração. A exploração deverá incluir, pelo menos, a exploração da prostituição de outrem ou outras formas de exploração sexual, o trabalho ou serviços forçados, a escravatura ou práticas similares à escravatura, a servidão ou a extracção de órgãos ${ }^{35}$.

A definição do tráfico de pessoas expressa pelo Protocolo é bastante complexa, pelo fato de abranger diversas condutas criminosas, perpetradas por distintos agentes em variados países. Nesse sentido, cabe aos Estados a adoção de medidas legislativas necessárias a fim de criminalizá-la ${ }^{36}$. Considerando-se tais especificidades, o mesmo conceito é incorporado à ordem jurídica moçambicana com a ratificação do Protocolo de Palermo (2000), pelo Conselho de Ministros, por intermédio da Resolução n. 87/2002, de 11 de dezembro. Essa ação surgiu numa atitude positiva de manifestação de interesse do Estado em contribuir para a prevenção e combate ao tráfico de pessoas ao nível doméstico e pelo alcance de prioridades comuns, assumidas aos níveis regional, continental e internacional.

A referida decisão, por parte de Moçambique, assenta no seu compromisso perante a Constituição da República de Moçambique (CRM) que o posiciona como um Estado de Direito, baseado no respeito e garantia dos direitos e liberdades fundamentais da pessoa humana. É, igualmente, reafirmada, na esfera do Direito Internacional, pelo art. 18, da CRM, ao preceituar que "os tratados internacionais, validamente aprovados e ratificados, vigoram na ordem jurídica moçambicana após a sua publicação oficial e enquanto vincularem internacionalmente o Estado de Moçambique", devendo, desse modo, nos termos do n. 2, do mesmo artigo, essas normas "[...] possuírem na ordem jurídica interna o mesmo valor que assumem os actos normativos infraconstitucionais emanados pela Assembleia da República e pelo

\footnotetext{
35 MOÇAMBIQUE. Resolução n. 87/2002, de 11 de dezembro de 2004. Ratifica o Protocolo Adicional à Convenção das Nações Unidas contra o Crime Organizado Transnacional Relativo à Prevenção, Repressão e Punição do Tráfico de Pessoas, em Especial Mulheres e Crianças. Boletim da República: Conselho de Ministros, Maputo: Imprensa Nacional, 2004. p. 1.

36 MACHADO, Bruno Amaral; VIEIRA, Priscila Brito Silva. Controle penal do tráfico de pessoas: construção jurídica, interações organizacionais e cooperação internacional. Revista de Direito internacional, Brasília, v. 13, n. 3, p. 484-503, 2016.
}

Governo, consoante a respectiva forma de recepção"37.

Esse aparato jurídico-constitucional dá formato ao Estado moçambicano para providenciar medidas visando ao enfrentamento do tráfico de pessoas, garantindo, por essa via, as salvaguardas referidas internacionalmente, tanto pela DUDH quanto pelo Protocolo de Palermo (2000). Tal fato se observa, porquanto a DUDH provê essas salvaguardas ao dispor sobre a universalidade dos direitos humanos, e o Protocolo, por sua vez, ao incidir sobre

[...] uma abordagem global e internacional, que inclua medidas destinadas a prevenir o tráfico, punir os traficantes e a proteger as vítimas, mediante a garantia dos seus direitos humanos e fundamentais, internacionalmente protegidos ${ }^{38}$.

Como resposta à esfera normativa internacional importa referir que a

[...] humanização do Direito Internacional Público e a consequente estruturação de um regime internacional sobre a matéria propiciaram de tal modo um desenvolvimento normativo em matéria de $\mathrm{TSH}^{39}$, que gera obrigações de devida diligência aos Estados, com vistas à proteção dos direitos humanos ${ }^{40}$.

Essa obrigação dos Estados-Membros das Nações Unidas impulsionou Moçambique a tomar parte desse processo, cuja responsabilidade se enquadra na realização de prestações positivas ou ações efetivas para a proteção e efetivação dos direitos fundamentais, assim como a assunção de tratados de natureza vinculante, que o obrigam a implementar medidas cabíveis para fazer cumprir internamente esses instrumentos traçados internacionalmente ${ }^{41}$.

Paralelamente à responsabilidade internacional e regional que o Ente Estatal haja adotado, o Estado mo\begin{tabular}{l}
\hline 37 MOÇAMBIQUE. Constituição da República de Moçambique (CRM). \\
Maputo: Plural, 2004. Disponível em: https://www.portaldogov- \\
erno.gov.mz/por/Media/Files/Constituicao-da-Republica-PDF. \\
Acesso em: 8 maio 2020. \\
$38 \quad$ MOÇAMBIQUE. Resolução n. 87/2002, de 11 de dezembro de \\
2004. Ratifica o Protocolo Adicional à Convenção das Nações Uni- \\
das contra o Crime Organizado Transnacional Relativo à Prevenção, \\
Repressão e Punição do Tráfico de Pessoas, em Especial Mulheres e \\
Crianças. Boletim da República: Conselho de Ministros, Maputo: Imp- \\
rensa Nacional, 2004. \\
39 A abreviatura TSH significa Tráfico de Seres Humanos. \\
40 SILVA, Waldimeiry Côrrea da. Regime Internacional de Enfrentamen- \\
to ao Tráfico de Pessoas: avanços e desafios para a proteção dos direitos \\
humanos. Rio de Janeiro: Lumen Juris, 2018. p. 4. \\
41 RODA, Arménio da. A dimensão global do tráfico humano: o tráfico \\
de pessoas aos olhos de Moçambique. São Paulo: Atarukas, 2019.
\end{tabular} 
çambicano tem o dever, no plano interno, de prestar ações positivas, traduzidas em políticas, programas ou ações específicas que concorrem para o enfrentamento do tráfico de pessoas ${ }^{42}$.

As ações positivas de Moçambique, no entanto, ao nível do ordenamento jurídico deram forma à legislação específica sobre o tráfico de pessoas, cujas expressões são a Lei n. 6/2008, de 09 de julho — conhecida como Lei sobre a Prevenção e Combate ao Tráfico de Pessoas, especialmente mulheres e crianças (Lei sobre Tráfico de Pessoas) ${ }^{43}$ e o Código Penal Moçambicano de 2014 $\left(\mathrm{CP}^{44}\right)$ - , que criminaliza a posse, transporte e tráfico de órgãos humanos ${ }^{45}$ e o tráfico de pessoas, nos termos dos Artigos 161 e 198, respectivamente. Isso veio a suprir, não somente, a falta de um conceito sobre o tráfico de pessoas em Moçambique, mas também a carência conceitual para o tráfico de partes do corpo humano, o que não estava satisfatoriamente contemplado pelo Protocolo de Palermo (2000), tampouco pela Declaração ${ }^{46}$ de Istambul ${ }^{47}$, assim como a legislação específica

42 RODA, Arménio da. A dimensão global do tráfico bumano: o tráfico de pessoas aos olhos de Moçambique. São Paulo: Atarukas, 2019.

43 MOÇAMBIQUE. Lei n. 6/2008, de 9 de julho. Dispõe sobre o regime jurídico aplicável à prevenção e combate ao tráfico de pessoas. Boletim da República, Maputo: Imprensa Nacional Disponível em: http://www.ilo.ch/dyn/natlex/docs/ELECTRONIC/86030/96743/F88437680/MOZ86030.pdf. Acesso em: 12 abr. 2020 .

44 A abreviatura CP significa Código Penal.

45 "Aquele que detiver, possuir, transportar e traficar partes ou órgãos humanos, internos ou externos, sangue, produtos de sangue ou tecidos do corpo humano em violação de normas [...]"; "Aquele que instigar com promessa de sucesso na vida sentimental ou em negócios ou de qualquer outra natureza induza o agente à prática dos actos referidos no número anterior [...]" e "Aquele que aliciar outrem, com o pagamento ou sua promessa, a qualquer título, conducente à prática dos actos previstos no n. 1 do presente artigo [...]". Os infratores que forem indiciados nos números referidos serão punidos com a pena de prisão de doze a dezasseis anos; com a pena de prisão de dezasseis a vinte anos e com a pena do número anterior, respectivamente (Lei n. 35/2014, de 31 de dezembro de 2014. Lei da Revisão do Código Penal (CP). Boletim da República, Maputo: Imprensa Nacional, 2014. Disponível em: http:/ /www.wlsa.org.mz/wpcontent/uploads/2014/11/Lei-35_2014Codigo_Penal.pdf. Acesso em: 21 jun. 2020).

46 A Declaração de Istambul sobre Tráfico de Órgãos e Turismo de Transplante foi elaborada em 2008, em Istambul, na Turquia, com objetivo de combater e minimizar o tráfico de órgãos e o turismo para transplante (TRANSPLANTE. Declaração de Istambul sobre Tráfico de Órgãos e Turismo de Transplante. Rio de Janeiro, 2008. Disponível em: http://www.transplante.ri.gov.br/Site/Arq/declaracaoistambul.pdf. Acesso em: 15 out. 2020).

47 SILVA, Waldimeiry Côrrea da; SOUZA, Caio Humberto Ferreira Dória de. O tráfico de órgãos no Brasil entre a lenda urbana à realidade: casos Pavesi e Operação Bisturi. Cadernos Temáticos sobre sobre tráfico que antecede o referido $\mathrm{CP}$, questão que é objeto de debates, pesquisas e direcionamento de ações, pelo Estado e por outros atores para sua compreensão e enfrentamento.

O crime de tráfico de pessoas em vigor em Moçambique é o que consta do Código Penal em voga, uma vez que neste, com base na alínea " $k$ ", do artigo $2^{\circ}$, foi revogada a preceituação do crime de tráfico de pessoas, enunciada pelo art. 10 da Lei n. 6/2008, de 09 de julho. Esse arranjo jurídico, que decorreu da revisão do Código Penal português de $1886^{48}$, o que esteve em vigor em Moçambique até 2014, impulsionou ao legislador a estabelecer, nos termos do artigo 198, que comete o crime de tráfico de pessoas:

[...] aquele que recrutar, transportar, acolher, fornecer ou receber uma pessoa, sob pretexto de emprego, formação ou aprendizagem, para fins de prostituição, trabalho forçado, escravatura, servidão involuntária ou servidão por dívida será punido com pena de prisão maior de dezasseis a vinte anos ${ }^{49}$.

Com efeito, a definição elaborada pelo Código Penal denota semelhança com o anterior, o qual se inspirava, também, no Protocolo de Palermo (2000), fato demonstrativo de que tanto o anterior quanto o conceito em vigor em Moçambique (o que consta do art. 198 do CP) são influenciados pelo Protocolo de Palermo (2000), tal como se atesta da leitura do art. 10 (revogado) da Lei n. 6/2008, que o definia como o ato de

[...] recrutar, transportar, acolher, fornecer ou receber uma pessoa, por quaisquer meios, incluindo sob pretexto de emprego doméstico ou no estrangeiro ou formação ou aprendizagem, para fins de prostituição, trabalho forçado, escravatura, servidão involuntária ou servidão por dívida ${ }^{50}$.

Tráfico de Pessoas: conceitos e tipologias de exploração. Brasília: Ministério da Justiça, p. 75-105. 2014. p. 75-105.

48 O Código Penal de Moçambique foi aprovado pela Lei n. 35/2014, de 31 de dezembro, por unanimidade pelo Parlamento moçambicano em substituição do Código Penal Português, legislação penal vigente desde 1886 (DW. Novo Código Penal de Moçambique traz muitas novidades. Disponível em: https://www.dw.com/pt-002/ novo-c $\% \mathrm{C} 3 \% \mathrm{~B} 3$ digo-penal-de-mo $\% \mathrm{C} 3 \% \mathrm{~A} 7$ ambique-traz-muitasnovidades/a-17790640. Acesso em: 16 out. 2020).

49 MOÇAMBIQUE. Lei n. 35/2014, de 31 de dezembro de 2014. Lei da Revisão do Código Penal (CP). Boletim da República, Maputo: Imprensa Nacional, 2014. Disponível em: http://www.wlsa.org. mz/wp-content/uploads/2014/11/Lei-35_2014Codigo_Penal.pdf. Acesso em: 21 jun. 2020.

50 MOÇAMBIQUE. Lei n. 6/2008, de 9 de julho. Dispõe sobre o regime jurídico aplicável à prevenção e combate ao tráfico de pessoas. Boletim da República, Maputo: Imprensa Nacional Dis- 
De igual modo, o conceito em vigor destaca três elementos na sua definição, os quais devem ser observados cumulativamente, nomeadamente: 1) ações (as condutas praticadas pelos traficantes); 2) meios (os meios a utilizar); e 3) resultados (o fim visado pelos autores do delito, isto é, a modalidade de exploração). Esse fato chama atenção, pois o cumprimento desses elementos é definido pelo art. 198, do CP, ao tipificá-lo como crime, o que exige a observância cumulativa de todos os seus elementos constitutivos, dificultando a denúncia, bem como a sua criminalização, em decorrência da dificuldade de identificação "cumulativa" de todos os elementos constitutivos do crime de tráfico de pessoas, desde a fase do recrutamento até o período de exploração.

$\mathrm{O}$ art. $9^{\circ}$ do CP é o que melhor explica a intenção do legislador, ao se referir sobre a necessidade da observância dos elementos, essencialmente, constitutivos do fato criminoso, que a lei criminal declarar ${ }^{51}$. Isso demonstra que o Direito Penal moçambicano estabelece o seu conteúdo e o limite para a interpretação e integração da lei criminal, marcado pela necessidade de constituição do Direito Penal humano, possível por meio da constitucionalização, que se dá por intermédio da interpretação das normas penais na óptica constitucional, justificando-se na necessidade de aperfeiçoar a interpretação de toda a lei com base nas normas fundamentais dos direitos humanos ${ }^{52}$.

Com efeito, o ponto a merecer atenção, no que concerne ao tratamento do crime de tráfico de pessoas, refere-se à necessidade de observância cumulativa de elementos constitutivos (condutas, meios e fins), o que conforma um óbice para a denúncia, assim como para a criminalização do ilícito, em decorrência da sua complexidade, de seus modi operandi diversificados desde a fase do recrutamento até o período de exploração, sem perder de vista o fato de esse crime ser de natureza organizada e transnacional, o que demanda o envolvimento de vários atores e múltiplos canais de contato para a sua execução.

ponível em: http://www.ilo.ch/dyn/natlex/docs/ELECTRONIC/86030/96743/F88437680/MOZ86030.pdf. Acesso em: 12 abr. 2020.

51 MOÇAMBIQUE. Lei n. 35/2014, de 31 de dezembro de 2014. Lei da Revisão do Código Penal (CP). Boletim da República, Maputo: Imprensa Nacional, 2014. Disponível em: http://www.wlsa.org. mz/wp-content/uploads/2014/11/Lei-35_2014Codigo_Penal.pdf. Acesso em: 21 jun. 2020.

52 ZAFFARONI, Eugenio Raúl. Derecho Penal Humano y poder en el siglo XXI: Conferencias de Guatemala, 2016. Disponível em: http://www.pensamientopenal.com.ar/system/files/2016/10/doctrina44188.pdf. Acesso em: 22 maio 2020.
A percepção dessa dificuldade, por parte do legislador, levou-o a fazer constar, na Lei sobre o Tráfico de Pessoas, os crimes conexos ${ }^{53}$, nomeadamente: a pornografia e exploração sexual ${ }^{54}$, a adoção para fins ilícitos ${ }^{55}$, o transporte e rapto ${ }^{56}$, o arrendamento de imóvel para fins de tráfico ${ }^{57}$, a publicidade e promoção do tráfico ${ }^{58}$, destruição de documentos de viagem ${ }^{59}$ e benefícios financeiros ${ }^{60}$, constantes nos artigos $11,12,13,14,15,16$ e $17^{61}$, respectivamente.

Vista nessa perspectiva, a Lei n. 6/2008, de 9 de julho, completa os objetivos de enfrentamento propostos no art. $2^{\circ}$, do Protocolo de Palermo (2000): prevenir e combater o tráfico de pessoas, prestando uma atenção especial às vítimas; proteger e ajudar as vítimas desse tráfico, respeitando plenamente os seus direitos humanos e promover a cooperação entre os Estados-Partes de forma a

53 Esses crimes resultam da dificuldade existente em provar se o crime de tráfico de pessoas, o qual pode configurar as diversas formas enunciadas, por este fato são denominados "crimes conexos" ao tráfico de pessoas.

54 Traficar com o fim de obter dinheiro, lucro ou qualquer outra vantagem, um cidadão moçambicano a cidadão estrangeiro, para casamento com o fim de adquirir, comprar, oferecer, vender ou trocar a pessoa para envolvimento em pornografia, exploração sexual e trabalho forçado, escravatura, servidão involuntária e servidão por dívidas.

55 Adoptar ou facilitar a adopção de pessoas com a finalidade de envolvimento na prostituição, exploração sexual e trabalho forçado, escravatura, servidão involuntária e servidão por dívidas.

56 Recrutar, contratar, adoptar, transportar ou raptar uma pessoa, mediante ameaça ou uso da força, fraude, engano, coação ou intimidação, com a finalidade de remoção ou venda de órgãos da referida pessoa".

57 "Conscientemente arrendar ou subarrendar, ou permitir a utilização de qualquer casa ou estabelecimento com a finalidade de promoção do tráfico de pessoas.

58 Fazer publicidade, imprimir, transmitir ou distribuir, ou causar a publicidade, publicação, impressão, transmissão ou distribuição, por quaisquer meios, incluindo o uso de tecnologia de informação e a Internet, ou qualquer brochura ou material de propaganda que promova o tráfico de pessoas.

59 Confiscar, esconder ou destruir o passaporte, os documentos de viagem, documentos ou pertences pessoais das vítimas do tráfico para impedir de abandonar o país ou buscarem ajuda de Governo ou das autoridades competentes.

60 Beneficiar conscientemente, financeiramente ou de outra forma, ou fazer uso do trabalho ou dos serviços de uma pessoa sujeita a uma condição de servidão involuntária, trabalho forçado ou escravatura.

61 MOÇAMBIQUE. Lei n. 6/2008, de 9 de julho. Dispõe sobre o regime jurídico aplicável à prevenção e combate ao tráfico de pessoas. Boletim da República, Maputo: Imprensa Nacional Disponível em: http://www.ilo.ch/dyn/natlex/docs/ELECTRONIC/86030/96743/F88437680/MOZ86030.pdf. Acesso em: 12 abr. 2020 . 
atingir esses objetivos ${ }^{62}$. Significa, efetivamente, enaltecer o papel do Protocolo de Palermo (2000), na qualidade de marco normativo geral que providencia aos Estados um alinhamento conceitual e facilita a cooperação internacional entre os países, com o objetivo de, ao nível interno, eles implantarem legislações penais ${ }^{63}$.

Essa conclusão surge do fato de a Lei moçambicana sobre o tráfico e pessoas, especialmente mulheres e crianças, estabelecer o regime jurídico interno aplicável a prevenção e combate ao tráfico de pessoas, em particular mulheres e crianças, nomeadamente a criminalização do tráfico de pessoas e atividades conexas e a proteção das vítimas, denunciantes e testemunhas ${ }^{64}$, mediante o estabelecimento de ações de coordenação com diversos atores nacionais e internacionais envolvidos no enfrentamento ao tráfico de pessoas nos planos nacional, regional, continental e internacional.

\section{Contexto e gênese das políticas públicas de prevenção e combate ao tráfico de pessoas em Moçambique}

O tráfico de pessoas é “[...] confrontado, muitas vezes, por quadros legislativos e políticas reguladoras insuficientes [...]" ${ }^{15}$. Esse problema acontece em quase todo o mundo. Por exemplo, o Relatório sobre o Tráfico de Pessoas, de 2016, demonstra o quanto esse ponto de insuficiência de legislação específica ao nível dos Estados é, ainda, notório:

\footnotetext{
62 MOÇAMBIQUE. Resolução n. 87/2002, de 11 de dezembro de 2004. Ratifica o Protocolo Adicional à Convenção das Nações Unidas contra o Crime Organizado Transnacional Relativo à Prevenção, Repressão e Punição do Tráfico de Pessoas, em Especial Mulheres e Crianças. Boletim da República: Conselho de Ministros, Maputo: Imprensa Nacional, 2004. p. 2.

63 MACHADO, Bruno Amaral; VIEIRA, Priscila Brito Silva. Controle penal do tráfico de pessoas: construção jurídica, interações organizacionais e cooperação internacional. Revista de Direito internacional, Brasília, v. 13, n. 3, p. 484-503, 2016.

${ }^{64}$ MOÇAMBIQUE. Lei n. 6/2008, de 9 de julho. Dispõe sobre o regime jurídico aplicável à prevenção e combate ao tráfico de pessoas. Boletim da República, Maputo: Imprensa Nacional Disponível em: http://www.ilo.ch/dyn/natlex/docs/ELECTRONIC/86030/96743/F88437680/MOZ86030.pdf. Acesso em: 12 abr. 2020.

65 UNESCO. Tráfico de Pessoas em Moçambique: Causas Principais e Recomendações. Police Paper, Paris, n. 14.1 (P), Série de relatórios sobre a pobreza, 2006. p. 1.
}

[...] different parts of the world are at different stages in the implementation of effective countertrafficking policy. [...]. In some parts of SubSaharan Africa, there is a need to develop legal frameworks; in parts of the world where antitrafficking legislation has been recently introduced (Southern Africa, North Africa, parts of the Middle East, parts of South America) capacitybuilding assistance to accelerate the use of national frameworks in accordance with international standards is more needed. In countries with longstanding legislation on trafficking in persons, for example, in European subregions, interventions should focus on identifying and protecting more victims, and convicting more traffickers ${ }^{66}$.

Nessa linha de argumentação, constata-se o fato de que diversos países estão em estágios de desenvolvimento incipientes, tanto em relação à elaboração quanto à implementação de suas políticas, o que denota, de certa maneira, lacunas identificadas pela UNESCO, assim como pelos Relatórios Globais sobre Tráfico de Pessoas de $2012^{67}$ e $2009^{68}$, que apontam, respectivamente, sobre a necessidade de cooperação entre os atores para providenciarem, mutuamente, assistência legislativa, assessoria para a planificação estratégica e desenvolvimento de políticas, a fortificação da justiça criminal e da resposta, garantindo a prevenção e assistência às vítimas, bem como as lacunas decorrentes do não estabelecimento de políticas e mecanismo de identificação das vítimas de tráfico de pessoas, em razão da insuficiente legislação na África Austral.

Outrossim, o Estado moçambicano desenvolveu ações para assegurar a inclusão de temáticas sobre a prevenção e combate do tráfico de pessoas nas agendas pública e política, podendo ser citadas as seguintes práticas: campanha da Southern African Network Against Trafficking and Abuse of Children (SANTAC), em 2002, a capacitação de jornalistas, a consciencialização da sociedade, por meio de comunicações públicas de

${ }_{66}$ UNODC. Global Report on Trafficking in Persons in 2016. Nova York: Publicação das Nações Unidas. 2016. p. 19. Disponível em: https://www.unodc.org/documents/data-and-analysis/ glotip/2016_Global_Report_on_Trafficking_in_Persons.pdf. Acesso em: 18 maio 2020.

67 UNODC. Global Report on Trafficking in Persons in 2016. Nova York: Publicação das Nações Unidas. 2016. p. 19. Disponível em: https://www.unodc.org/documents/data-and-analysis/ glotip/2016_Global_Report_on_Trafficking_in_Persons.pdf. Acesso em: 18 maio 2020.

68 UNODC. Global Report on Trafficking in Persons in 2009. Nova York: Publicação das Nações Unidas. 2009. Disponível em: https:// www.unodc.org/documents/Global_Report_on_TIP.pdf. Acesso em: 11 maio 2020. 
membros do Parlamento, do Presidente, o Procurador-Geral e os Ministérios do Interior e da Justiça ${ }^{69}$.

Essas ações que visavam mostrar o comprometimento desses órgãos do Estado foram reforçadas pelas ações das organizações da sociedade civil (OSC) e organismos internacionais (OI), como aponta UNESCO:

\begin{abstract}
[...] existem muitas organizações nacionais que foram formadas [...]. Há muitas mais organizações internacionais envolvidas como, por exemplo, a IOM, UNODC, UNESCO, UNICEF, Save the Children Noruega, WLRI/CEDPA, USAID, bem como as Embaixadas da Noruega, do Reino Unido dos Estados Unidos da América. A maior parte ou estão a gerir e a financiar a pesquisa ou a providenciar programas de assistência técnica na luta contra o tráfico ${ }^{70}$.
\end{abstract}

No mesmo período, constatam-se como ações relevantes o envolvimento de crianças nas campanhas de sensibilização, a colaboração transfronteiriça entre as ONGs (organizações não governamentais) dos países vizinhos de Moçambique (particularmente a África do Sul e a Suazilândia), com o objetivo de trocar experiências técnicas e operacionais sobre as maneiras de lidar com as vítimas de tráfico e de providenciar o apoio mútuo entre essas organizações e representantes governamentais de alto nível dos Estados. Esses fóruns contaram com a participação da Polícia da República de Moçambique (PRM) e a South African Police Service (SAPS), mediante acordos de cooperação técnica-operacional celebrados entre as duas instituições, assim como entre a PRM e a Polícia da Suazilândia, por meio de acordos entre as instituições policiais dos três Estados, que fazem fronteira terrestre na região sul do País. Esses acordos bilaterais, assim como trilaterais, de cooperação técnico-operacional e estratégica são comuns entre Moçambique e os países que partilham a mesma fronteira, em toda a extensão da sua fronteira terrestre, mormente Zimbabwe, Zâmbia, Malawi e Tanzânia:

esta colaboração apoia organizações em
Moçambique e na África do Sul, incluindo
representantes governamentais de alto nível. A
polícia da África do Sul e de Moçambique encontra-
se envolvida em discussões com as ONGs para
partilhar experiências operacionais sobre como
lidar com as vítimas, resgatar as vítimas e sobre

69 UNESCO. Tráfico de Pessoas em Moçambique: Causas Principais e Recomendações. Police Paper, Paris, n. 14.1 (P), Série de relatórios sobre a pobreza, 2006.

70 UNESCO. Tráfico de Pessoas em Moçambique: Causas Principais e Recomendações. Police Paper, Paris, n. 14.1 (P), Série de relatórios sobre a pobreza, 2006. as formas como os traficantes operam. As ONGs têm encontros regulares transfronteiriços em vários níveis. ${ }^{71}$

Com efeito, denota-se um enorme esforço dos diversos atores de Moçambique, em particular — em direção ao entendimento do problema, porquanto era o caso de introduzir a "questão do tráfico de pessoas" na agenda governamental. Essa época serviu como um espaço que privilegiou o reconhecimento do problema do tráfico nos planos global, continental, regional e nacional - um período em que ao Estado, uma vez ratificados instrumentos internacionais relevantes sobre a matéria tinham a obrigação, como asseveram Corrêa da Silva ${ }^{72}$ e Roda ${ }^{73}$, de desenvolver ações concretas na contextura interna, em adição ao fato de que Moçambique estava a receber pressões da Suazilândia e da África do Sul, Estados que o consideravam como sendo um país de trânsito do tráfico de pessoas, especialmente para a África do Sul.

Seja expresso, ainda, o fato de que Moçambique era considerado nesse período o principal corredor do tráfico de pessoas, particularmente, de mulheres e crianças. Entrementes, a África de Sul, país que partilham a mesma fronteira, "o principal destino das vítimas de TP" 7475 .

\subsection{Determinantes internacionais, regionais e nacionais para a elaboração de políticas públicas de prevenção e combate ao tráfico de pessoas em Moçambique}

Moçambique ratificou dois instrumentos internacionais, quais sejam: a Convenção das Nações Unidas contra o Crime Organizado Transnacional ${ }^{76}$ e o Proto-

UNESCO. Tráfico de Pessoas em Moçambique: Causas Principais e Recomendações. Police Paper, Paris, n. 14.1 (P), Série de relatórios sobre a pobreza, 2006.

72 SILVA, Waldimeiry Côrrea da. Regime Internacional de Enfrentamento ao Tráfico de Pessoas: avanços e desafios para a proteção dos direitos humanos. Rio de Janeiro: Lumen Juris, 2018.

73 RODA, Arménio da. A dimensão global do tráfico bumano: o tráfico de pessoas aos olhos de Moçambique. São Paulo: Atarukas, 2019.

${ }_{74}$ TP significa Tráfico de Pessoas.

75 MAGODE, Joaquim; JOSÉ, Patrício; CONGOLO, Frederico; CADEADO, Calton; PATRÍCIO, António; LINDY, Rafael. Tráfico de Pessoas em Moçambique, em particular de crianças. Moçambique: Procuradoria Geral da República, 2014. p. 12.

76 A Convenção das Nações Unidas contra o Crime Organizado Transnacional, também conhecida como Convenção de Palermo, é o principal instrumento global de combate ao crime organizado transnacional. O instrumento foi aprovado em Nova York pela As- 
colo de Palermo (2000). Na mesma senda participou, em 2009, da elaboração do Plano de Acção Estratégico Decenal para o Combate ao Tráfico de Pessoas, em particular de Mulheres e Crianças (2009-2019) ${ }^{77}$, um empreendimento da Southern African Development Community (SADC) dedicado à prevenção e combate ao tráfico de pessoas, especialmente mulheres e crianças no interior dos Estados-membros da SADC e na região da África Austral, sendo que, dentre diversos aspectos destaca:

[...] a investigação e a partilha de informação, como uma área importante de intervenção estratégica na luta contra o TP, [...] apela ainda à partilha de documentação, de experiências e de práticas eficazes de prevenção e combate ao $\mathrm{TP}^{78}$.

Mormente essas ações resultam de esforços iniciados pelo Estado moçambicano em reconhecimento da existência da problemática do tráfico de pessoas nos planos internacional e nacional. Como se observa, referindo-se à dimensão do tráfico, especificamente de crianças em Moçambique, a pesquisa encomendada pela Procuradoria Geral da República (PGR), em 2014, constatou que

[...] o problema de Tráfico de Crianças (TC) tem sido objecto de reflexão, quer das autoridades estatais, quer das organizações da sociedade civil (OSC). Esta reflexão trouxe resultados que se revelaram satisfatórios com a publicação de estudos sobre o TP em Moçambique, bem como a publicitação dos direitos humanos das mulheres e das crianças. Foi assim que foram ratificados instrumentos legais internacionais $^{79}$.

Esse esforço normativo foi desenvolvido por Moçambique dada a natureza global e regional do tráfico de pessoas, assim como no sentido de mostrar que "[...] está comprometido com a problemática do TP, o que se traduz na prevenção, na repressão dos traficantes e na

sembleia-Geral da ONU em 15 de novembro de 2000, data em que foi colocada à disposição dos Estados-membros para assinatura, e entrou em vigor no dia 29 de setembro de 2003.

77 A Comunidade de Desenvolvimento da África Austral (SADC) adoptou o Plano Estratégico de Acção da SADC de 10 Anos para o Combate ao Tráfico de Pessoas, em Especial de Mulheres e Crianças (2009-2019), em Kinshasa, na República Democrática do Congo (RDC), em 2009. O objetivo do bloco regional era de enviar uma mensagem clara de que os Estados-Membros consideravam a prevenção e o combate ao TP uma prioridade que exigia uma atenção focada e esforços concertados em toda a África Austral.

78 SADC. Prevenção e Combate ao Tráfico de Pessoas: Lições da Região da SADC. Folheto Informativo sobre Politicas, Gaborone, p. 1-39, jan. 2017.

79 MAGODE, Joaquim; JOSÉ, Patrício; CONGOLO, Frederico; CADEADO, Calton; PATRÍCIO, António; LINDY, Rafael. Tráfico de Pessoas em Moçambique, em particular de crianças. Moçambique: Procuradoria Geral da República, 2014. assistência e protecção às vítimas, em nível doméstico e internacional" ${ }^{\prime \prime 0}$.

Além da adesão e ratificação dos instrumentos referidos, Moçambique adotou o Protocolo da Southern African Development Community (SADC) sobre Gênero e Desenvolvimento ${ }^{81}$, que considera o tráfico de pessoas como uma forma de violência baseada no gênero. Esse instrumento regional foi ratificado por Moçambique, em prossecução dos interesses concordados ao nível da região da SADC, relacionados à necessidade da inclusão de questões de género no programa de ação da SADC e nas suas iniciativas de construção comunitária, o que constitui um fator-chave para o desenvolvimento sustentável da África Austral ${ }^{82}$.

Essa motivação, inclusive, reafirma o comprometimento dos Estados-Membros da SADC a não discriminar nenhuma pessoa em razão do sexo ou gênero, como determina o número 2 do art. $6^{\circ}$ do Tratado da SADC ${ }^{83}$. A isso se acrescenta a noção de que a igualdade-equidade de gênero é um direito humano e fundamental, o que impulsionou Moçambique, assim como os países da África Austral, a assinar, ratificar ou aderir a Convenção das Nações Unidas sobre a Eliminação de Todas as Formas de Discriminação Contra as Mulheres (CEDAW) ${ }^{84}$.

No enfrentamento ao tráfico de pessoas ao nível da SADC, a importância do Protocolo da SADC sobre

80 MAGODE, Joaquim; JOSÉ, Patrício; CONGOLO, Frederico; CADEADO, Calton; PATRÍCIO, António; LINDY, Rafael. Tráfico de Pessoas em Moçambique, em particular de crianças. Moçambique: Procuradoria Geral da República, 2014. p. 28.

81 O Protocolo da Southern African Development Community (SADC) sobre Gênero e Desenvolvimento foi aprovado em Johannesburg, República da África do Sul, aos 17 de agosto de 2008 (SADC. Protocolo da SADC sobre Gênero e Desenvolvimento. Joanesburgo, 2008. Disponível em: https://www.eisa.org.za/pdf/sadc2008protocol2.pdf. Acesso em: 10 jun. 2020). Foi ratificado por Moçambique por meio da Resolução n. 45/2010, de 2 de novembro de 2010.

82 SADC. Protocolo da SADC sobre Gênero e Desenvolvimento. Joanesburgo, 2008. Disponível em: https://www.eisa.org.za/pdf/sadc2008protocol2.pdf. Acesso em: 10 jun. 2020.

83 O Tratado da SADC foi adotado em Windhoek, na Namíbia, aos 17 de agosto de 1992 e ratificado pela Resolução n. 3/1993, de 1 de junho de 1983 (SADC. Manual Institucional de Identidade Institucional da SADC. Gaborone: Secretariado da SADC, 2017).

${ }^{84}$ A Convenção das Nações Unidas sobre a Eliminação de Todas as Formas de Discriminação Contra as Mulheres (CEDAW) foi aprovada pela Assembleia Geral das Nações Unidas, aos 18 de dezembro de 1979 e ratificado pela Resolução n. 4/93, de 2 de junho de 1993 (ONU MULHERES. Convenção das Nações Unidas sobre a Eliminação de Todas as Formas de Discriminação Contra as Mulberes. Disponível em: http://www.onumulheres.org.br/wp-content/uploads/2013/03/ convencao_cedaw.pdf. Acesso em: 15 jun. 2020). 
Gênero e Desenvolvimento encontra fundamento ao dispor, na alínea "d" do art. 11, que os Estados-Parte devem adoptar legislação, políticas e programas para garantir o desenvolvimento e a proteção de raparigas e rapazes contra a exploração económica, do tráfico de pessoas e de todas as formas de violência, incluindo o abuso sexual. Essa preceituação é reforçada pelas alíneas “a”, "b", “c", "d" e "e", do art. 20 do mesmo instrumento, que recomendam aos Estados a promulgação e adoção de disposições legislativas específicas para prevenir o tráfico de pessoas e prestar serviços holísticos às vítimas, de modo a garantir sua reintegração na sociedade; criar mecanismos que garantam que as autoridades e instituições possam prover a proteção dos direitos ao nível nacional, regional e internacional; estabelecer mecanismos harmonizados de coleta de dados sobre o tráfico de pessoas, de modo a assegurar uma sistematização e monitoramento eficazes; estabelecer acordos bilaterais e multilaterais para executar ações conjuntas de prevenção e combate ao tráfico de pessoas nos países de origem, trânsito e destino; e assegurar a capacitação, conscientização e sensibilização sobre o tráfico de pessoas ${ }^{85}$.

Dentro do ordenamento jurídico nacional, especificamente, a resposta governamental à problemática do tráfico de pessoas se assenta em princípios constitucionais enunciados pelo n. ${ }^{\circ} 4$ do art. $2^{\circ}$ da CRM de 2004, referente à soberania e legalidade, ao predispor que as "[...] normas constitucionais prevalecem sobre todas as restantes normas do ordenamento jurídico", assim como no enunciado do n. 1 do art. 40, da CRM de 2004, referente ao direito à vida, que dispõe que "todo o cidadão tem direito à vida e à integridade física e moral e não pode ser sujeito à tortura ou a tratamentos cruéis e desumanos" ${ }^{\prime 6}$. Recorda-se que, de acordo com o art. 43, da mesma Constituição, os preceitos constitucionais relativos aos direitos fundamentais devem ser interpretados e integrados de harmonia com a Declaração Universal dos Direitos Humanos e a Carta Africana dos Direitos Humanos e dos Povos, o que serve de garantia formal dos direitos e liberdades fundamentais dos cidadãos.

\footnotetext{
85 SADC Protocolo da SADC sobre Gênero e Desenvolvimento. Joanesburgo, 2008. Disponível em: https://www.eisa.org.za/pdf/sadc2008protocol2.pdf. Acesso em: 10 jun. 2020.

86 MOÇAMBIQUE. Constituição da República de Moçambique (CRM). Maputo: Plural, 2004. Disponível em: https://www.portaldogoverno.gov.mz/por/Media/Files/Constituicao-da-Republica-PDF. Acesso em: 8 maio 2020.
}

Tal fato sucede, uma vez que esses direitos fundamentais protegidos constitucionalmente são, universalmente, reafirmados na DUDH e na Carta Africana dos Direitos Humanos e dos Povos. O art. $1^{\circ}$ e o n. ${ }^{\circ} 2$ do art. 29 da DUDH preceituam, respectivamente, que "todos os seres humanos nascem livres e iguais em dignidade e direitos" e que

[...] no exercício de seus direitos e liberdades, todo ser humano estará sujeito apenas às limitações determinadas pela lei, exclusivamente com o fim de assegurar o devido reconhecimento e respeito dos direitos e liberdades de outrem e de satisfazer as justas exigências da moral, da ordem pública e do bem-estar de uma sociedade democrática ${ }^{87}$.

De igual forma, na mesma intenção da DUDH, os artigos $4^{\circ}$ e $5^{\circ}$, da Carta Africana dos Direitos Humanos e dos Povos, referem, respectivamente, o seguinte:

[...] a pessoa humana é inviolável. Todo ser humano tem direito ao respeito da sua vida e à integridade física e moral da sua pessoa. Ninguém pode ser arbitrariamente privado desse direito" e que "Todo indivíduo tem direito ao respeito da dignidade inerente à pessoa humana e ao reconhecimento da sua personalidade jurídica. Todas as formas de exploração do homem, nomeadamente a escravatura $^{88}$, o tráfico de pessoas, a tortura física ou moral e as penas ou tratamentos cruéis, desumanos ou degradantes são proibidos ${ }^{89}$.

Com efeito, a incorporação desses instrumentos internacionais na ordem jurídica nacional serviu de base para propor políticas públicas de enfrentamento ao tráfico de pessoas em Moçambique, considerando que a partir desse exercício o Estado se viu obrigado a cumprir com os compromissos internacionais por si celebrados, ato que se fundamenta no disposto pela Resolução n. ${ }^{\circ}$ 32/2010, de 30 de agosto, sobre a Política Externa de Moçambique, onde, na alínea “m”, do n. 3, estabelece como um dos Princípios Fundamentais da Política Externa da República de Moçambique “[...] a observância das normas do direito internacional, de tratados e acordos internacionais, validamente aprovados e rensa Nacional, 1981. 
ratificados pelos órgãos competentes do Estado" ${ }^{90}$.

Nessa conjuntura, o Estado moçambicano serviu-se da articulação formal aferida pela Resolução, numa atitude positiva de manifestação de interesse em contribuir para a prevenção e combate do tráfico de pessoas e no alcance de prioridades comuns, assumidos aos níveis regional, continental e internacional, tendo em vista contribuir para o reforço da paz e segurança internacional, bem como para o progresso harmonioso e bem-estar da humanidade ${ }^{91}$, considerando que o tráfico de pessoas não se tornou, apenas, um problema de segurança nacional, mas também ao nível do mundo, cuja, indústria vem se mostrando crescente influenciada pela globalização, corrupção governamental e crime organizado ${ }^{92}$.

Em suma, com a aprovação do Protocolo de Palermo (2000), diversos arranjos político-diplomáticos foram realizados pelos Estados-Partes no sentido de incorporar essa agenda ao nível interno, o que era prenúncio de que os Estados estavam interessados em atender a agenda global de prevenir, punir e combater o tráfico de pessoas.

Com base em tal pretexto, Moçambique desenvolveu uma série de atividades com vistas a garantir a prevenção e combate ao tráfico de pessoas, especialmente mulheres e crianças. Assim, inspirado nas determinações do Protocolo de Palermo (2000), o país desenvolveu ações, que se descreve ${ }^{93}$, na figura 1 , como resposta às determinações estabelecidas na atividade prioritária — "medidas legislativas e políticas", constando do Plano desenhado ao nível da SADC ${ }^{94}$.

90 MOÇAMBIQUE. Resolução n. 32/2010, de 30 de agosto de 2010. Aprova a Política Externa de Moçambique. Boletim da República: Conselho de Ministros, Maputo: Imprensa Nacional, 2010

91 MOÇAMBIQUE. Resolução n. 32/2010, de 30 de agosto de 2010. Aprova a Política Externa de Moçambique. Boletim da República: Conselho de Ministros, Maputo: Imprensa Nacional, 2010.

92 PARENTE, Tara M. Human Trafficking: Identifying forced labour in multinational corporations \& the implications of ability. Revista de Direito internacional, Brasília, v. 11, n. 1, p. 146-161, 2014.

93 NHATAVE, Guirino Dinis José. Tráfico de Pessoas na SADC: Um Olhar Sobre a Construção da Agenda de Moçambique na Prevenção e Combate ao Tráfico de Pessoas na SADC. Revista Moçambicana de Estudos Internacionais, Moçambique: Instituto Superior de Relações Internacionais, v. 1, n. 1, p. 187-204, janeiro, 2019. Disponível em: https://www.academia.edu/39408387/Revista_ Mo\%C3\%A7ambicana_de_Estudos_Internacionais_Vol_1_no_1_ Janeiro-Junho_2019. Acesso em: 2 jun. 2020.

${ }_{94}$ O Plano Estratégico Decenal de Combate ao Tráfico de Pessoas especialmente Mulheres e Crianças foi elaborado em cumprimento das recomendações do Protocolo de Palermo (2000) para atender a questão do tráfico de pessoas com enfoque nas especificidades da
Tabela 1 - Grau de cumprimento das recomendações do Plano Estratégico Decenal de Combate ao Tráfico de Pessoas especialmente mulheres e crianças ao nível da SADC

\begin{tabular}{|c|c|}
\hline $\begin{array}{l}\text { PONTOS } \\
\text { FORTES }\end{array}$ & $\begin{array}{l}\text { - Ratificação de Instrumentos } \\
\text { Internacionais e Regionais que } \\
\text { abordam sobre a Prevenção e } \\
\text { Combate ao Tráfico de Pessoas, } \\
\text { especialmente Mulheres e Crianças. } \\
\text { - Existência da Legislação Específica } \\
\text { sobre o Tráfico de Pessoas e Código } \\
\text { Penal Moçambicano de 2014; } \\
\text { - Aprovação do Decreto n. }{ }^{\circ} 11 / 2008 \text {, } \\
\text { de } 29 \text { de abril - Introduz o Bilhete } \\
\text { de Identidade (BI) para o cidadão } \\
\text { nacional através de elementos } \\
\text { biométricos; } \\
\text { - Decreto n. } 13 / 2008 \text {, de } 29 \text { de abril } \\
\text { - Cria o novo modelo de Passaporte } \\
\text { para cidadãos nacionais, baseado em } \\
\text { elementos biométricos e electrónicos; }\end{array}$ \\
\hline $\begin{array}{l}\text { PONTOS } \\
\text { FRACOS }\end{array}$ & $\begin{array}{l}\text { - O Art. 198, referente ao Tráfico } \\
\text { de Pessoas no Código Penal } \\
\text { moçambicano de 2014, não se inspira } \\
\text { ao Protocolo de 2000; } \\
\text { - falta de Regulamentação da Lei sobre } \\
\text { Tráfico de Pessoas, especialmente } \\
\text { Mulheres e Crianças; } \\
\text { - inexistência de Plano Nacional de } \\
\text { Prevenção e Combate ao Tráfico de } \\
\text { Pessoas. }\end{array}$ \\
\hline OPORTUNIDADES & $\begin{array}{l}\text { - Todos Estados-Membros ratificaram } \\
\text { a Convenção das Nações Unidas sobre } \\
\text { o Crime Organizado Transnacional e o } \\
\text { Protocolo de Palermo 2000; } \\
\text { - todos os Estados-Membros da } \\
\text { SADC aderiram ao Plano Estratégico } \\
\text { Decenal de Combate ao Tráfico de } \\
\text { Pessoas, especialmente Mulheres e } \\
\text { Crianças. }\end{array}$ \\
\hline AMEAÇAS & $\begin{array}{l}\text { - Existência de alguns Estados } \\
\text { da SADC que não ratificaram } \\
\text { Instrumentos Regionais Cooperação } \\
\text { Jurídica e Judiciária, referentes à } \\
\text { Prevenção e Combate ao Tráfico de } \\
\text { Pessoas, especialmente Mulheres e } \\
\text { Crianças (Protocolo da SADC sobre } \\
\text { a Extradição e o Protocolo da SADC } \\
\text { sobre Ajuda Mútua Judiciária em } \\
\text { Matéria Penal); } \\
\text { - existência de alguns Estados da } \\
\text { SADC que não possuem legislação } \\
\text { específica sobre o Tráfico de Pessoas, } \\
\text { especialmente Mulheres e Crianças } \\
\text { - existência de alguns Estados da } \\
\text { SADC que ainda não possuem Planos } \\
\text { Nacionais de prevenção e combate ao } \\
\text { Tráfico de Pessoas. }\end{array}$ \\
\hline
\end{tabular}

região da África Austral. 
Da interpretação da tabela acima, "pontos fortes", se denota um avanço no desenvolvimento da resposta do Estado diante da complexidade do tráfico de pessoas, tanto interna, quanto externamente. Em decorrência dos referidos avanços, existem aspectos negativos, descritos como "pontos fracos" e "ameaças". Os pontos fracos são a inexistência, na legislação nacional, de um conceito de tráfico de pessoas que se conforma com a definição apresentada pelo Protocolo de Palermo (2000), a falta de regulamentação da Lei sobre e a inexistência de um Plano Nacional de Prevenção e Combate ao Tráfico de Pessoas, especialmente mulheres e crianças. As ameaças, por sua vez, estão relacionadas à existência de alguns Estados da SADC que não possuem legislação específica e respectivos planos nacionais, países que não ratificaram o Protocolo da SADC sobre a Extradição e o Protocolo da SADC sobre Ajuda Mútua e Judiciária em Matéria Penal ${ }^{95}$, o que impacta, negativamente, a prevenção e combate ao tráfico de pessoas em Moçambique e na SADC.

Os aspectos negativos referenciados são, igualmente, apontados pelo Relatório sobre o Tráfico de Pessoas em Moçambique, de 2018, publicado em 2019, pela Embaixada dos Estados Unidos da América, demonstrando que Moçambique não satisfaz os padrões para a eliminação do tráfico de pessoas, por ainda não ter finalizado o Plano Nacional para a Prevenção e Combate ao Tráfico de Pessoas e por não ter regulamentado, ainda, a Lei específica sobre o Tráfico de Pessoas ${ }^{96}$. Tal posição também é sustentada pela juíza Vitalina Papadakis que aponta como inquietações a falta de regulamentação da lei, a inexistência de centros de acolhimento de vítimas, o número exíguo de casos que chega aos tribunais, a inexistência de um plano de ação nacional para o combate ao tráfico de pessoas, a não inclusão de todas as questões referentes ao tráfico de pessoas no Programa Quinquenal do Governo (PQG - 2014-2019), o qual

\footnotetext{
95 NHATAVE, Guirino Dinis José. Tráfico de Pessoas na SADC: Um Olhar Sobre a Construção da Agenda de Moçambique na Prevenção e Combate ao Tráfico de Pessoas na SADC. Revista Moçambicana de Estudos Internacionais, Moçambique: Instituto Superior de Relações Internacionais, v. 1, n. 1, p. 187-204, janeiro, 2019. Disponível em: https://www.academia.edu/39408387/Revista_ Mo\%C3\%A7ambicana_de_Estudos_Internacionais_Vol_1_no_1_ Janeiro-Junho_2019. Acesso em: 2 jun. 2020.

96 EMBAIXADA DOS EUA. Relatório sobre o Tráfico de Pessoas em Moçambique de 2018. Maputo: Departamento do Estado, 2019. Disponível em: https://mz.usembassy.gov/wp-content/uploads/ sites/182/MOZAMBIQUE-2018-TIP-Report-Narrative-FINAL18JUNE2018-Port-004.pdf. Acesso em: 1 maio 2020.
}

faz referência, apenas, ao tráfico de crianças, a redução de esforços para processar judicialmente e condenar os traficantes, entre outras ${ }^{97}$.

Essas constatações, todavia, não ignoram esforços desenvolvidos por Moçambique, iniciados internamente em 2008, com a aprovação da Lei n. ${ }^{\circ}$ 6/2008, de 9 de julho, nos quais se inclui o

[...] aumento dos esforços através da identificação e referência para os cuidados de significativamente mais vítimas do tráfico e o aumento da formação de agentes da linha da frente, nomeadamente agentes policiais e oficiais de migração, e formou inspectores de trabalho pela primeira vez. O governo aumentou os esforços para prevenir o tráfico com a convocação do Grupo Nacional de Referência (NRG) para coordenar os esforços anti tráfico, financiamento de campanhas de sensibilização para educar o público nas áreas rurais e urbanas, e formação de respondedores da linha da frente sobre abordagens centradas nas vítimas ${ }^{98}$.

O desenvolvimento dessas ações, por parte de Moçambique, justificou a sua elevação ao Nível $2^{99}$ (Tier 2) ${ }^{100}$, uma classificação que é providenciada pelo Departamento dos Estados Unidos, baseado nas ações do governo no cumprimento dos padrões mínimos de enfrentamento ao tráfico de pessoas ${ }^{101}$.

PAPADAKIS, Vitalina Carmo. Moçambique: Tráfico Humano e Crime Organizado. The Pontifical Academy of Sciences. Vaticano, 2019. Disponível em: http://www.pas.va/content/accademia/en/publications/scriptavaria/africanwomenjudges/papadakis.pdf. Acesso em: 27 maio 2020.

98 EMBAIXADA DOS EUA. Relatório sobre o Tráfico de Pessoas em Moçambique de 2018. Maputo: Departamento do Estado, 2019. Disponível em: https://mz.usembassy.gov/wp-content/uploads/ sites/182/MOZAMBIQUE-2018-TIP-Report-Narrative-FINAL18JUNE2018-Port-004.pdf. Acesso em: 1 maio 2020.

99 O Nível 2 corresponde aos países cujos governos cumprem totalmente os padrões mínimos de legislação de proteção às vítimas de tráfico, mas estão envidando esforços significativos para o seu cumprimento. O Nível 2 Lista em observação, designado em inglês Tier 2 Watch List corresponde ao mesmo que o Nível 2, mas apresentam o aumento significativo de vítimas, não denotam esforços significativos do enfrentamento à problemática, em relação aos períodos anteriores, mas já demonstra o compromisso de adotar medidas futuras. O Nível 3 corresponde aos países cujos governos não cumprem totalmente os padrões mínimos e não estão fazendo esforços significativos para fazê-lo. O Nível 1, designado em inglês Tier 1, corresponde aos países cujos governos cumprem integralmente os padrões mínimos de legislação de proteção às vítimas de tráfico.

100 PAPADAKIS, Vitalina Carmo. Moçambique: Tráfico Humano e Crime Organizado. The Pontifical Academy of Sciences. Vaticano, 2019. Disponível em: http://www.pas.va/content/accademia/en/publications/scriptavaria/africanwomenjudges/papadakis.pdf. Acesso em: 27 maio 2020.

101 EMBAIXADA DOS EUA. Relatório sobre o Tráfico de Pessoas 
Partindo da compreensão que constata que as medidas legislativas ou programáticas, que incluem as alterações na legislação, implementação de planos de ação bem concebidos, regimes de proteção das vítimas e mecanismos nacionais de referência contribuem para aperfeiçoar a identificação das vítimas e a eficácia da justiça penal ${ }^{102}$, julga-se claro que as ações de regulamentação da Lei sobre o tráfico de pessoas e da aprovação do Plano nacional permitiriam a ampliação e o aperfeiçoamento dos mecanismos de prevenção e combate ao tráfico de pessoas em Moçambique.

A Regulamentação da Lei impulsionaria uma melhor atuação dos órgãos de administração da justiça e dos demais poderes públicos envolvidos nessa missão. $\mathrm{O}$ Plano, por sua vez, serviria de base para o fortalecimento da coordenação e cooperação entre os órgãos públicos, entre estes e as organizações internacionais e não governamentais, e vice-versa, assim como a definição dos objetivos, atores e suas responsabilidades, metas, orçamentação para o alcance dos resultados previstos e o respectivo monitoramento, partindo do pressuposto de que as ações de enfrentamento demandam uma intervenção cooperativa e colaborativa entre os diversos atores estatais e não estatais, mediante uma abordagem multidisciplinar e transversal.

\section{Jurisprudência}

O Relatório sobre o Tráfico de Pessoas, de 2018 demonstra uma relativa melhoria na capacidade das autoridades nacionais em rastrear e avaliar os padrões e fluxos do tráfico de pessoas, sobretudo nos últimos dez anos. De forma exemplificativa, o documento relata que "[...] em 2009, apenas 26 países tinham alguma instituição que recolhia e divulgava sistematicamente dados sobre casos de tráfico de pessoas, enquanto, até 2018, o número aumentou para $65 " .{ }^{103}$

em Moçambique de 2018. Maputo: Departamento do Estado, 2019. Disponível em: https://mz.usembassy.gov/wp-content/uploads/ sites/182/MOZAMBIQUE-2018-TIP-Report-Narrative-FINAL18JUNE2018-Port-004.pdf. Acesso em: 1 maio 2020.

102 UNODC. Relatório Global sobre o Tráfico de Pessoas 2018. Nova York: Publicação das Nações Unidas. 2018. Disponível em: https://www.unodc.org/documents/lpo-brazil//Topics_TIP/Publicacoes/TiP_PT.pdf. Acesso em: 22 maio 2020.

103 UNODC. Relatório Global sobre o Tráfico de Pessoas 2018. Nova York: Publicação das Nações Unidas. 2018. Disponível em: https://www.unodc.org/documents/lpo-brazil//Topics_TIP/Publi-
Com efeito, com vistas a dar maior visibilidade de processos bem-sucedidos e, ao mesmo tempo, promover a conscientização sobre a realidade do tráfico de pessoas, o Escritório das Nações Unidas contra Crime e Drogas desenvolveu, em 2014, um portal denominado Human trafficking Knowledge Portal (ou Sherloc), que hospeda uma base de dados de jurisprudência sobre casos oficialmente documentados de tráfico de pessoas. Trata-se de um portal que objetiva

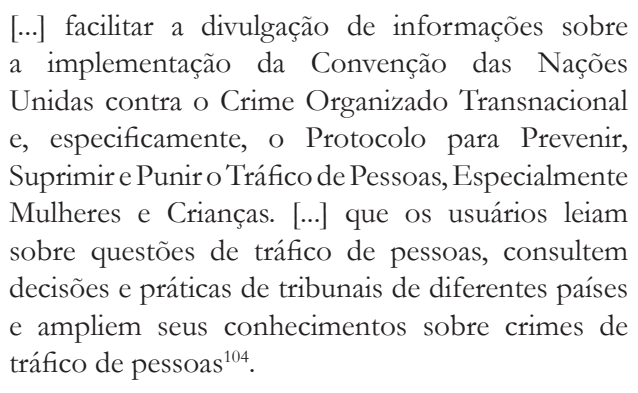

O referido portal apresenta três bases de dados ${ }^{105}$ de acordo com a figura abaixo:

Figura 1 - Bases de dados da UNODC

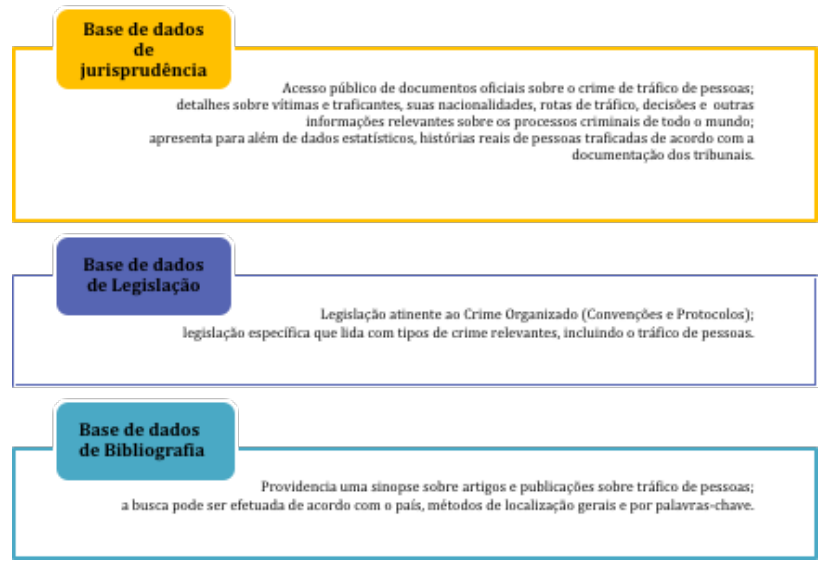

De acordo com essa base de dados, especificamente, a que trata sobre jurisprudência sobre o tráfico de pessoas $^{106}$, Moçambique demonstra registro de, apenas, um caso julgado, como se pode deduzir do gráfico $1^{107}$ :

cacoes/TiP_PT.pdf. Acesso em: 22 maio 2020.

104 UNODC. Human Trafficking Knowledge Portal: Case Law Database. Disponível em: https://sherloc.unodc.org/cld/v3/htms/ cldb/index.html?lng=en. Acesso em: 14 jun. 2020.

105 UNODC. Human Trafficking Knowledge Portal: Case Law Database. Disponível em: https://sherloc.unodc.org/cld/v3/htms/ cldb/index.html?lng=en. Acesso em: 14 jun. 2020.

106 UNODC. Human Trafficking Knowledge Portal: Case Law Database. Disponível em: https://sherloc.unodc.org/cld/v3/htms/ cldb/index.html?lng=en. Acesso em: 14 jun. 2020.

107 O Gráfico 1 representa, apenas, a compilação de dados sobre casos julgados na região da África Austral, região onde Moçambique está inserido e desenvolve ações em coordenação e cooperação com os países da região em cumprimento das recomendações, tanto do 
Gráfico 1 - Número de casos por Estado Membro da SADC

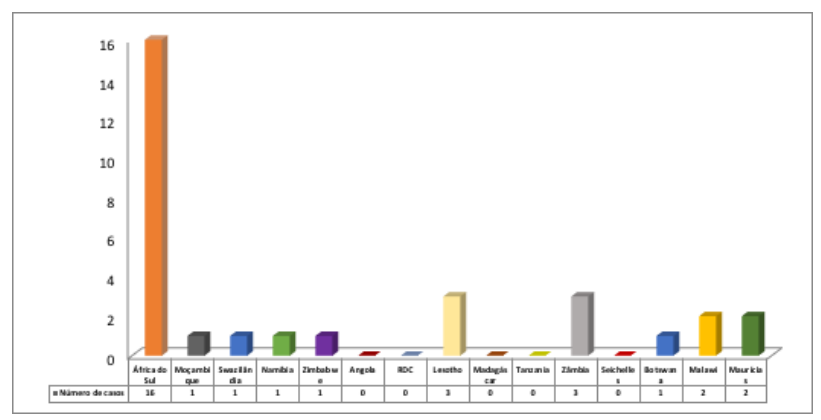

De acordo com a informação fornecida pela referida base de dados, trata-se de um caso de tráfico de uma menor de 11 anos de idade, de nacionalidade moçambicana, vítima de tráfico interno. A criança foi entregue a um curandeiro como garantia de um empréstimo no valor de $Z A^{108} 7000$, (aproximadamente U\$ 904). Em processo criminal, o caso foi julgado pela $1^{\mathrm{a}}$ instância do Tribunal Judicial Provincial. Esse caso foi decidido em 2010. Quando, porém, o caso foi julgado, não havia previsão legal em Moçambique que impedisse ou punisse a venda ou compra de seres humanos. Como tal, o crime foi definido como tráfico de pessoas, no quadro da Lei sobre a Prevenção e Combate ao Tráfico de Pessoas Lei n. ${ }^{\circ}$ 6/2008, de 9 de julho de 2008, no entanto, foi classificado como tráfico de pessoas, tendo se aplicado uma pena de 7 e 6 anos de prisão efetiva para os dois $\operatorname{acusados}^{109}$, respectivamente.

De acordo com dados que constam da tabela 1, retirados do Informe Anual da Procuradoria Geral da República de Moçambique (PGR) de $2017^{110}$, no ano de 2016, foram instaurados 19 processos, contra 95 de 2015, representando um decréscimo de 76 processos, correspondente a $80 \%$. Foram proferidos despachos de acusação em 17 processos, em um recaiu despacho de abstenção e um encontra-se em fase de instrução preparatória.

Protocolo, quanto do Plano Estratégico Decenal de Combate ao Tráfico de Pessoas especialmente Mulheres e Crianças.

${ }_{108}$ ZAR significa Rand - Moeda oficial da República da África do Sul. O Rand foi criado em 1961, cujo nome vem da abreviação de Witwatersrand, que, por sua vez, é a abreviação de White-waters-ridge, que significa "Montanha das Águas Brancas", sendo uma referência a maior reserva de ouro do País.

109 UNODC. Human Trafficking Knowledge Portal: Case Law Database. Disponível em: https://sherloc.unodc.org/cld/v3/htms/ cldb/index.html?lng=en. Acesso em: 14 jun. 2020.

110 PGR. Informe Anual de 2017 da Procuradoria-geral à Assembleia da República. Moçambique: Procuradoria Geral da República, 2017. Disponível em: http://www.pgr.gov.mz/images/documentos/ informe-anual/Informe_pgr_2017.pdf. Acesso em: 23 maio 2020.
Tabela 2 - Tráfico de pessoas

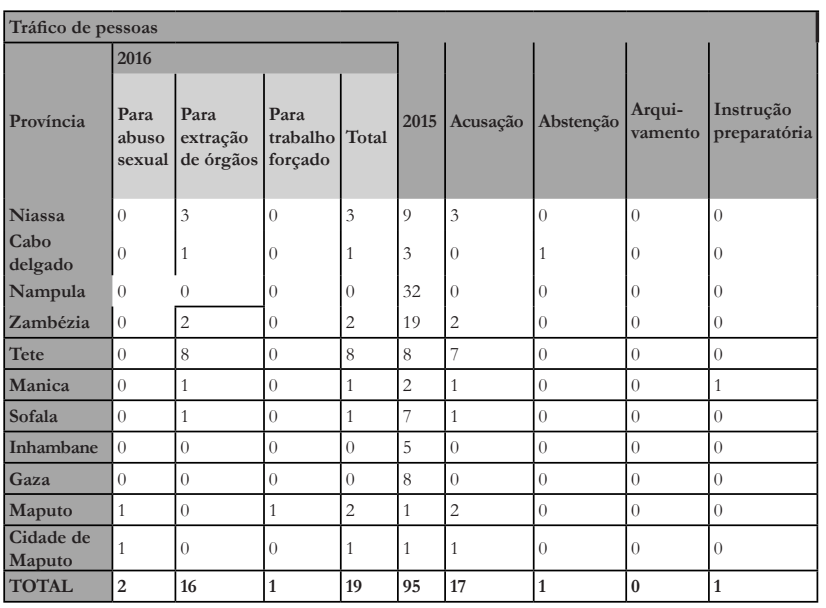

De acordo com o referido informe, em 2017, estavam em curso ações de:

[...] cooperação internacional para a prevenção e combate ao tráfico de pessoas, principalmente ao nível da região, [...]. [adesão] ao sistema de gestão e colecta de dados de tráfico de pessoas, da SADC, harmonizando-o com o nosso sistema jurídico ${ }^{111}$.

A inexistência de dados estatísticos sobre o tráfico de pessoas foi recentemente abordada por Vitalina Papadakis, na Cúpula de Mulheres Juízas e Procuradoras Africanas sobre Tráfico de Pessoas e Criminalidade Organizada, realizada em 2019, na Casina Pio IV, Cidade de Vaticano, onde, utilizando o estudo encomendado pela PGR, referiu que as poucas informações estatísticas disponíveis sobre o tráfico de pessoas são imprecisas $^{112}$, assim como o fato de não existirem "dados estatísticos [consolidados] sobre casos identificados, acusados e julgados"113.

Esses esforços, sobretudo no que se refere à inclusão de informações na base de dados da SADC, constituem um avanço para Moçambique, não somente no contexto regional, mas também internacional. De efeito, a Procuradora-Geral da República asseverou a existência de desafios, embora estejam em curso ações de cooperação

111 PGR. Informe Anual de 2017 da Procuradoria-geral à Assembleia da República. Moçambique: Procuradoria Geral da República, 2017. Disponível em: http://www.pgr.gov.mz/images/documentos/ informe-anual/Informe_pgr_2017.pdf. Acesso em: 23 maio 2020. 112 MAGODE, Joaquim; JOSÉ, Patrício; CONGOLO, Frederico; CADEADO, Calton; PATRÍCIO, António; LINDY, Rafael. Tráfico de Pessoas em Moçambique, em particular de crianças. Moçambique: Procuradoria Geral da República, 2014.

113 PAPADAKIS, Vitalina Carmo. Moçambique: Tráfico Humano e Crime Organizado. The Pontifical Academy of Sciences. Vaticano, 2019. Disponível em: http://www.pas.va/content/accademia/en/publications/scriptavaria/africanwomenjudges/papadakis.pdf. Acesso em: 27 maio 2020. 
internacional, que incluem Moçambique no sistema da gestão e coleta de dados de tráfico de pessoas da SADC, assim como a necessidade de garantir a harmonização dessa base ao sistema jurídico moçambicano ${ }^{114}$.

Nesse diapasão, a operacionalização desse sistema da gestão de base é crucial para que Moçambique consiga enviar os dados de casos julgados na base de dados da UNODC, de modo a sustentar a referida base e responder de modo adequado ao que o Protocolo de Palermo (2000) determina atinente ao intercâmbio de informações sobre o tráfico de pessoas.

\section{Considerações finais}

O conceito do tráfico de pessoas em Moçambique é inspirado no Protocolo de Palermo (2000). Mencionado conceito surge no esforço de o Estado moçambicano providenciar um quadro jurídico nacional de prevenção e combate ao tráfico de pessoas em observância aos instrumentos normativos internacionais e regionais de proteção aos direitos humanos e fundamentais das pessoas.

Apesar dessas ações que permitiram Moçambique formular políticas públicas de prevenção e combate ao tráfico de pessoas, o País se ressente da falta de regulamentação da Lei sobre o tráfico de pessoas e da inexistência de um plano de ação nacional para atender a questão do tráfico de pessoas.

Moçambique está, atualmente, no Nível 2 sobre o cumprimento dos padrões de formulação e implementação de legislação sobre tráfico de pessoas, o que demonstra seu compromisso em prevenção e combate ao tráfico de pessoas, especialmente mulheres e crianças. Esse reconhecimento decorre das avaliações a que o Estado vem sendo submetido desde o desenvolvimento de esforços iniciados em 2000, com a adesão à Convenção de Palermo e ao Protocolo de Palermo, instrumentos internacionais que definem uma agenda global de enfrentamento a criminalidade organizada transnacional e ao tráfico de pessoas, respectivamente.

A base de dados da UNODC expressa, tão somente,

114 PGR. Informe Anual de 2017 da Procuradoria-geral à Assembleia da República. Moçambique: Procuradoria Geral da República, 2017. Disponível em: http://www.pgr.gov.mz/images/documentos/ informe-anual/Informe_pgr_2017.pdf. Acesso em: 23 maio 2020. um caso julgado de Moçambique. Tal situação minimiza os esforços do País no enfrentamento ao tráfico de pessoas, uma vez que os dados de jurisprudência sobre casos oficialmente documentados de tráfico de pessoas iriam aumentar a visibilidade de processos bem-sucedidos e, ao mesmo tempo, promover a conscientização sobre a dimensão desse crime, internamente.

\section{Referências}

ANISTIA INTERNACIONAL. Informe 2017/2018 sobre o Estado dos Direitos Humanos no Mundo. Reino Unido: Amnesty International, 2018.

CARTA AFRICANA. Resolução n. 9/88, de 25 de agosto de 1981. Ratifica a Carta africana dos Direitos Humanos e dos Povos de 1979. Boletim da República: Conselho de Ministros. Maputo: Imprensa Nacional, 1981.

SILVA, Waldimeiry Côrrea da. Regime Internacional de Enfrentamento ao Tráfico de Pessoas: avanços e desafios para a proteção dos direitos humanos. Rio de Janeiro: Lumen Juris, 2018.

SILVA, Waldimeiry Côrrea da; SOUZA, Caio Humberto Ferreira Dória de. O tráfico de órgãos no Brasil entre a lenda urbana à realidade: casos Pavesi e Operação Bisturi. Cadernos Temáticos sobre Tráfico de Pessoas: conceitos e tipologias de exploração. Brasilia: Ministério da Justiça, p. 75-105. 2014.

DUDH. Declaração Universal dos Direitos Humanos. Nova York: 1948. Disponível em: https://nacoesunidas.org/ wp-content/uploads/2018/10/DUDH.pdf. Acesso em: 5 maio 2020.

DW. Novo Código Penal de Moçambique traz muitas novidades. Disponível em: https://www.dw.com/pt-002/ novo-c $\%$ C3\%B3digo-penal-de-mo $\%$ C3\% A 7 ambiquetraz-muitas-novidades/a-17790640. Acesso em: 16 out. 2020.

EMBAIXADA DOS EUA. Relatório sobre o Tráfico de Pessoas em Moçambique de 2018. Maputo: Departamento do Estado, 2019. Disponível em: https://mz.usembassy. gov/wp-content/uploads/sites/182/MOZAMBIQUE-2018-TIP-Report-Narrative-FINAL-18JUNE2018-Port-004.pdf. Acesso em: 1 maio 2020.

FDC. Violência contra Menores em Moçambique: revisão da literatura. Maputo: KULA Estudos e Pesquisa Aplicada, 2008. 
KANIMAMBO. Breve enquadramento da situação actual em Moçambique. 2020. Disponível em: https:/ /www.uccla.pt/ sites/default/files/mk_doc_enquadramento_18set_2. pdf. Acesso em: 25 jun. 2020.

MACHADO, Bruno Amaral; VIEIRA, Priscila Brito Silva. Controle penal do tráfico de pessoas: construção jurídica, interações organizacionais e cooperação internacional. Revista de Direito internacional, Brasília, v. 13, n. 3, p. 484-503, 2016.

MAGODE, Joaquim; JOSÉ, Patrício; CONGOLO, Frederico; CADEADO, Calton; PATRÍCIO, António; LINDY, Rafael. Tráfico de Pessoas em Moçambique, em particular de crianças. Moçambique: Procuradoria Geral da República, 2014.

MARIANO, Esmeralda; BRAGA, Carla; MOREIRA, Andrea. Estudo sobre o Tráfico de órgãos e partes de corpo bumano na Região Sul de Moçambique. Maputo: CEMIRDE, 2016.

MOÇAMBIQUE. Constituição da República de Moçambique (CRM). Maputo: Plural, 2004. Disponível em: https:// www.portaldogoverno.gov.mz/por/Media/Files/Constituicao-da-Republica-PDF. Acesso em: 8 maio 2020.

MOÇAMBIQUE. Lei n. 35/2014, de 31 de dezembro de 2014. Lei da Revisão do Código Penal (CP). Boletim da República, Maputo: Imprensa Nacional, 2014. Disponível em: http://www.wlsa.org.mz/wp-content/ uploads/2014/11/Lei-35_2014Codigo_Penal.pdf. Acesso em: 21 jun. 2020.

MOÇAMBIQUE. Lei n. 6/2008, de 9 de julho. Dispõe sobre o regime jurídico aplicável à prevenção e combate ao tráfico de pessoas. Boletim da República, Maputo: Imprensa Nacional Disponível em: http:/ /www.ilo. ch/dyn/natlex/docs/ELECTRONIC/86030/96743/ F88437680/MOZ86030.pdf. Acesso em: 12 abr. 2020.

MOÇAMBIQUE. Resolução n. 32/2010, de 30 de agosto de 2010. Aprova a Política Externa de Moçambique. Boletim da República: Conselho de Ministros, Maputo: Imprensa Nacional, 2010.

MOÇAMBIQUE. Resolução n. 87/2002, de 11 de dezembro de 2004. Ratifica o Protocolo Adicional à Convenção das Nações Unidas contra o Crime Organizado Transnacional Relativo à Prevenção, Repressão e Punição do Tráfico de Pessoas, em Especial Mulheres e Crianças. Boletim da República: Conselho de Ministros, Maputo: Imprensa Nacional, 2004.
MOREIRA, Andrea; MARIANO, Esmeralda. Estudo sobre o Tráfico de Pessoas, órgãos e artes de corpo bumano no Norte de Moçambique. Maputo: CEMIRDE, 2018.

NAÇÕES UNIDAS BRASIL. A Declaração Universal dos Direitos Humanos de 1948. Disponível em: https:/ / nacoesunidas.org/direitoshumanos/declaracao/>. Acesso em: 25 maio 2020 .

NHATAVE, Guirino Dinis José. Tráfico de Pessoas na SADC: Um Olhar Sobre a Construção da Agenda de Moçambique na Prevenção e Combate ao Tráfico de Pessoas na SADC. Revista Moçambicana de Estudos Internacionais, Moçambique: Instituto Superior de Relações Internacionais, v. 1, n. 1, p. 187-204, janeiro, 2019. Disponível em: https://www.academia.edu/39408387/ Revista_Mo\%C3\%A7ambicana_de_Estudos_Internacionais_Vol_1_no_1_Janeiro-Junho_2019. Acesso em: 2 jun. 2020.

ONU MULHERES. Convenção das Nações Unidas sobre a Eliminação de Todas as Formas de Discriminação Contra as Mulheres. Disponível em: http://www.onumulheres.org. br/wp-content/uploads/2013/03/convencao_cedaw. pdf. Acesso em: 15 jun. 2020.

OPHENTA. Carta Africana dos Direitos do Homem e dos Povos. Disponível em: https://www.ophenta.org.mz/ wp-content/uploads/2017/03/Carta-Africana-Direitos-Humanos-1.pdf. Acesso em: 12 abr. 2020.

PAPADAKIS, Vitalina Carmo. Moçambique: Tráfico Humano e Crime Organizado. The Pontifical Academy of Sciences. Vaticano, 2019. Disponível em: http://www. pas.va/content/accademia/en/publications/scriptavaria/africanwomenjudges/papadakis.pdf. Acesso em: 27 maio 2020 .

PARENTE, Tara M. Human Trafficking: Identifying forced labour in multinational corporations \& the implications of ability. Revista de Direito internacional, Brasília, v. 11, n. 1, p. 146-161, 2014.

PGR. Informe Anual de 2017 da Procuradoria-geral à Assembleia da República. Moçambique: Procuradoria Geral da República, 2017. Disponível em: http://www.pgr. gov.mz/images/documentos/informe-anual/Informe_pgr_2017.pdf. Acesso em: 23 maio 2020.

RABEN, Sarah Myers. The ISIS eradication of Christians and yazidis: human trafficking, denocide, and the missing international efforts to stop it. Revista de Direito Internacional, Brasília, v. 15, n. 1, p. 239-253, 2018. 
RODA, Arménio da. A dimensão global do tráfico bumano: o tráfico de pessoas aos olhos de Moçambique. São Paulo: Atarukas, 2019.

SADC. Manual Institucional de Identidade Institucional da SADC. Gaborone: Secretariado da SADC, 2017.

SADC. Prevenção e Combate ao Tráfico de Pessoas: Lições da Região da SADC. Folheto Informativo sobre Politicas, Gaborone, p. 1-39, jan. 2017.

SADC. Protocolo da SADC sobre Gênero e Desenvolvimento. Joanesburgo, 2008. Disponível em: https://www.eisa. org.za/pdf/sadc2008protocol2.pdf. Acesso em: 10 jun. 2020.

SADC. Tráfico de Pessoas na Região da SADC: Folheto Informativo sobre Políticas, p. 1-10, ago. 2016.

TRANSPLANTE. Declaração de Istambul sobre Tráfico de Órgãos e Turismo de Transplante. Rio de Janeiro, 2008. Disponível em: http://www.transplante.rj.gov.br/Site/ Arq/declaracaoistambul.pdf. Acesso em: 15 out. 2020.

UNESCO. Tráfico de Pessoas em Moçambique: Causas Principais e Recomendações. Police Paper, Paris, n. 14.1 (P), Série de relatórios sobre a pobreza, 2006.

UNICEF. Proteção da criança: Manual para Parlamentares n. 7. Suíça: União Inter parlamentar, 2004.

UNODC. Global Report on Trafficking in Persons in 2009. Nova York: Publicação das Nações Unidas. 2009. Disponível em: https://www.unodc.org/documents/Global_Report_on_TIP.pdf. Acesso em: 11 maio 2020.

UNODC. Global Report on Trafficking in Persons in 2012. Nova York: Publicação das Nações Unidas. 2012. Disponível em: https://www.unodc.org/documents/data-and-analysis/glotip/Trafficking_in_Persons_2012_ web.pdf. Acesso em: 9 maio 2020.

UNODC. Global Report on Trafficking in Persons in 2014. Nova York: Publicação das Nações Unidas. 2014. Disponível em: https://www.unodc.org/documents/lpobrazil//Topics_TIP/Publicacoes/GLOTIP_2014_ full_report.pdf. Acesso em: 10 maio 2020.

UNODC. Global Report on Trafficking in Persons in 2016. Nova York: Publicação das Nações Unidas. 2016. p. 19. Disponível em: https://www.unodc.org/documents/ data-and-analysis/glotip/2016_Global_Report_on_ Trafficking_in_Persons.pdf. Acesso em: 18 maio 2020.

UNODC. Relatório Global sobre o Tráfico de Pessoas 2018. Nova York: Publicação das Nações Unidas. 2018. Di- sponível em: https://www.unodc.org/documents/lpobrazil//Topics_TIP/Publicacoes/TiP_PT.pdf. Acesso em: 22 maio 2020.

UNODC. Human Trafficking Knowledge Portal. Disponível em: https://sherloc.unodc.org/cld/en/v3/htms/index.html. Acesso em: 15 maio 2020.

UNODC. Human Trafficking Knowledge Portal: Case Law Database. Disponível em: https://sherloc.unodc.org/ $\mathrm{cld} / \mathrm{v} 3 / \mathrm{htms} / \mathrm{cldb} /$ index.html?lng=en. Acesso em: 14 jun. 2020.

ZAFFARONI, Eugenio Raúl. Derecho Penal Humano y poder en el siglo XXI: Conferencias de Guatemala, 2016. Disponível em: http:/ / www.pensamientopenal.com.ar/ system/files/2016/10/doctrina44188.pdf. Acesso em: 22 maio 2020. 
Para publicar na Revista de Direito Internacional, acesse o endereço eletrônico www.rdi.uniceub.br ou www.brazilianjournal.org.

Observe as normas de publicação, para facilitar e agilizar o trabalho de edição. 